\title{
The evolution and biological correlates of hand preferences in anthropoid primates
}

\author{
Kai R. Caspar ${ }^{1 *}$, Fabian Pallasdies ${ }^{2}$, Larissa Mader ${ }^{1}$, Heitor Sartorelli $^{3}$, Sabine Begall ${ }^{1}$ \\ ${ }^{1}$ Department of General Zoology, University of Duisburg-Essen, Universitaetsstraße 5, 45141 Essen, Germany \\ ${ }^{2}$ Institute for Theoretical Biology, Department of Biology, Humboldt-Universität zu Berlin, Berlin, Germany \\ ${ }^{3}$ Independent researcher
}

\begin{abstract}
The evolution of human right-handedness has been intensively debated for decades. Manual lateralization patterns in non-human primates have the potential to elucidate evolutionary determinants of human handedness. However, restricted species samples and inconsistent methodologies are limiting comparative phylogenetic studies. By combining original data with published literature reports, we assembled data on hand preferences for standardized object manipulation in 1,806 individuals from 38 species of anthropoid primates, including monkeys, apes, and humans. Based on that, we employ quantitative phylogenetic methods to test prevalent hypotheses on the roles of ecology, brain size and tool use in primate handedness evolution. We confirm that human right-handedness represents an unparalleled extreme among anthropoids and found taxa displaying significant population-level handedness to be notably rare. Species-level direction of manual lateralization was largely uniform among non-human primates and neither correlated with phylogeny nor with any of the selected biological predictors. In contrast, we recovered highly variable patterns of hand preference strength, which show signatures of both ecology and phylogeny. In particular, terrestrial primates tend to display weaker hand preferences than arboreal species. These results challenge popular ideas on primate handedness evolution, especially the postural origins hypothesis. Furthermore, they point to a potential adaptive benefit of disparate lateralization strength in primates, a measure of hand preference that has often been overlooked in the past. Finally, our data show that human lateralization patterns do not align with trends found among other anthropoids, suggesting that unique selective pressures gave rise to the unusual hand preferences displayed by our species.
\end{abstract}

Key words: handedness, laterality, hemispheric dominance, tube task, comparative cognition, postural origins hypothesis

\section{Introduction}

Pronounced right-handedness is a universal trait among extant human populations (Coren \& Porac, 1977; Raymond \& Pontier, 2004; Faurie et al., 2005) and might be an ancient attribute of the genus Homo ( Toth, 1985; Lozano et al., 2017). A significant expression of manual lateralization at population-level is not exclusive to humans but the universal proportion of approximately 85-95 \% right-handers in our species appears to be an unmatched extreme among primates (Meguerditchian et al., 2013). Furthermore, individual humans tend to be strongly handed with ambiguous hand preferences being extremely rare (Cochet \& Vauclair, 2012), which is also unusual when compared to many other primate lineages (Westergaard \& Suomi, 1996; Hopkins et al., 2011). Therefore, both strength and direction of population-level manual lateralization in humans must be considered remarkable. 
Handedness is a behavioral consequence of functional asymmetries in the brain (Amunts et al., 1996; Häberling \& Corballis, 2016; Sha et al., 2021). Accordingly, right-handedness results from unilateral specializations in the left hemisphere and vice versa. In anthropoid primates, which encompass monkeys, apes, and humans, asymmetries of the precentral gyrus in the primary motor cortex show a particular association with individual hand preferences (Yousry et al., 1997; Phillips \& Sherwood, 2005; Dadda et al., 2006; Sha et al., 2021). Nevertheless, the proximate reasons for the expression of individual handedness in humans and other anthropoids, including its genetic basis and the influence of brain areas located outside of the motor cortex, are by no means fully understood (Rogers, 2009; Hopkins et al. 2013; Ocklenburg et al., 2014; Schmitz et al., 2017a; Richards et al., 2021). For this paper, however, we exclusively focus on the evolutionary underpinnings of population-level manual lateralization.

The origins of pronounced population-level right-handedness in the human lineage have traditionally been linked to the emergence of complex communication mediated by manual gestures and language, which are also predominantly processed in the left hemisphere (Corballis, 1991; Annett, 2002; Meguerditchian et al., 2013; Ocklenburg et al., 2014; Prieur et al., 2019). However, current evidence suggests that manual and language lateralization are not nearly as tightly correlated as traditionally believed and functional ties between these phenomena remain unidentified (Fitch \& Braccini, 2013; Ocklenburg et al., 2014; Schmitz et al., 2017b). It has also been established that various nonhuman primates show significant asymmetries in hand-use at the individual and population-level in a variety of tasks including manual gestures and bimanual actions ( MacNeilage, 2007; Hopkins et al., 2013; Meguerditchian et al., 2013; Regaiolli et al., 2016). Nevertheless, reports of significant population-level biases are largely confined to a comparatively small number of species and the distribution of individuals across hand preference categories is always far more balanced than in humans. For instance, olive baboons (Papio anubis), Western gorillas (Gorilla gorilla), and chimpanzees (Pan troglodytes) all show a significant population-level right hand bias for bimanual manipulation but the portion of right-handers among these species is only around $50 \%$ (Vauclair et al., 2005; Hopkins et al., 2011). Still, it is essential to discern what underlies these comparatively weak population-level hand preference patterns that emerged across the primate order to unravel the origins of pronounced right-handedness in our species (MacNeilage, 2007).

The most influential conjecture to explain how primate hand preference patterns evolved is the postural origins hypothesis (POH) (MacNeilage et al., 1987; MacNeilage, 2007). Considering galagos as models, the $\mathrm{POH}$ assumes that hypothetical insectivorous primate ancestors exhibited a righthand bias to support their body on vertical substrates, while the left-hand specialized for fast grasping movements, the so-called ballistic reaching (Ward, 1998). Based on this, the POH predicts that with the emergence of anthropoid primates, which exhibit arboreal quadrupedalism and more refined digit control, the right hand became adopted to manipulate objects during foraging (MacNeilage et al., 1987). Hence, it proposes that all anthropoids share a right-hand bias for manipulation, which would find its most extreme expression in humans (MacNeilage, 2007; MacNeilage et al., 1987). In the anatomically less derived strepsirrhines, the left hand is instead expected to be dominant (MacNeilage, 2007). However, the POH has been drastically modified by more recent authors (Hopkins et al., 2011; Meguerditchian et al., 2013; Morino et al., 2017). The novel interpretation proposes (in conflict with the original POH) that arboreal monkeys and apes should display a left-hand bias for manipulation. Their right hand would provide the necessary postural support, retaining the hypothesized ancestral primate pattern laid out by MacNeilage et al. (1987). Terrestrial lineages, however, would no longer be bound to reserve the right hand for posture stabilization and are expected to evolve right hand preferences for fine motor skills, eventually leading to the human condition. Hence, the novel $\mathrm{POH}$ expects that left-handedness is prevalent in arboreal groups, while a preponderance of right-handedness should be restricted to terrestrial 
primate species (Meguerditchian et al., 2013). In contrast, the original POH expects to find a righthandedness trend in all anthropoids, regardless of their ecology.

In addition to these considerations, it has been prominently proposed that tool use facilitated the evolution of hand preferences in humans to allow for more efficient object handling ( Kimura, 1979; Frost, 1980), but this idea has also been extended to nonhuman primates that habitually use tools (Cashmore et al., 2008; Prieur et al., 2019). Moreover, neuroanatomical studies demonstrated that the expression of overall neural lateralization and hemispheric independence positively correlates with absolute brain size in primates (Rilling \& Insel, 1999; Karolis et al., 2019; Ardesch et al., 2021). Such a scaling relation was already hypothesized by Ringo et al. (1994) and implies that the strength of individual handedness could also be tied to absolute brain size (Hopkins, 2013b); the concept does, however, not concern the direction of hand preferences. Hence, it can be hypothesized that larger-brained primates should evolve greater manual lateralization strength to reduce the amount of interhemispheric communication needed to accomplish manipulative tasks. Complementary to these predictions, there is evidence that absolute brain size is positively correlated with foot preference strength for grasping among parrot species (Kaplan \& Rogers, 2021; but note that this study did not control for phylogeny; see also Brown and Magat, 2011).

Thus testable hypotheses on primate hand preference evolution have long been established, but none of them has so far been tested within quantitative evolutionary frameworks (Hopkins, 2013a). Studies in comparative cognition increasingly rely on phylogenetically informed modelling to estimate how and when specific behaviors evolved (MacLean et al., 2012; ManyPrimates et al., 2019; Krasheninnikova et al., 2020). Such approaches can provide estimates of ancestral states and allow researchers to quantify the pace as well as the influence of phylogeny and ecological variables on cognitive evolution (MacLean et al., 2012). However, to yield meaningful results, dense taxonomic sampling of species and a consistent testing scheme are required (Freckleton et al., 2002; Krasheninnikova et al., 2020). For research on primate hand preferences, this means that subjects from different species need to engage in the same experimental task to assess lateralization. Standardization is particularly important since both the strength and the direction of individual hand preferences can be task-dependent and because the expression of manual lateralization correlates positively with motor complexity ( Vauclair et al., 2005; Blois-Heulin et al., 2007; Lilak \& Phillips, 2008; Meguerditchian et al., 2015; Caspar et al., 2018). Bimanual actions that involve both hands and which spontaneously occur during food manipulation or tool use are particularly suitable to detect hand preferences (Meguerditchian et al., 2013), while non-gestural unimanual actions such as grasping often do not elicit pronounced group or individual-level lateralized responses (Papademetriou et al., 2005; Rogers, 2009; Hopkins et al., 2013a). For comparative approaches in primates, tool handling is only of limited use as a model behavior, because habitual tool use is only found in few lineages (Musgrave \& Sanz, 2018). Therefore, bimanual actions related to foraging present themselves as suitable candidates for comparative studies on hand preferences in these animals.

A simple and widely applicable experiment to determine anthropoid primate hand preferences is the so-called tube task (Hopkins, 1995): A subject is handed a PVC tube filled with desired food. To extract it, one hand must hold the tube while the other has to engage in the more complicated action of retrieving the food mesh, thereby revealing biases in hand use dominance. Results from the tube task have been demonstrated to robustly correlate with hemispheric asymmetries in various primate groups (New World monkeys: Phillips \& Sherwood, 2005; Old World monkeys: Margiotoudi et al., 2019; apes: Hopkins \& Cantalupo, 2004; Dadda et al., 2006) and to be intraindividually consistent across re-tests, even if these were separated by several years (Hopkins et al., 2001). Furthermore, its 
simplicity allows uniform testing of a wide range of species in captive as well as natural settings (Zhao et al., 2012).

Here we compiled a comprehensive multispecies tube task dataset to test pertaining hypotheses on the evolution of primate manual lateralization by means of phylogenetically informed modelling. This way we provide a broad comparative perspective on the origins of human right-handedness in the context of object manipulation.

\section{Materials and Methods}

\section{Subjects}

We analyzed the expression of hand preferences for object manipulation in the tube task, as well as potential factors influencing their evolution, for a dataset of anthropoid primates (infraorder Simiiformes: New World monkeys (Platyrrhini), Old World monkeys (Cercopithecoidea), and apes (Hominoidea)) from 38 species. Data from 501 individuals belonging to 26 primate species were collected in the tube task paradigm (see below) between September 2017 and May 2020 in 39 institutions in Europe, Brazil, and Indonesia (Table 1). Of these species, 14 had never been tested in the tube task before. Additional datasets were drawn from the literature, resulting in a total sample of 1,806 individuals from 38 species and 20 genera, covering all anthropoid primate families except Aotidae. Data for humans were derived from Cochet and Vauclair (2012). In this study, participants had to use one hand to repeatedly retrieve pieces of paper out of a plastic cylinder while the other one had to tilt and stabilize the receptacle. We considered this bimanual testing paradigm as functionally equivalent to the tube task. Our complete study sample with respective data sources is included in Supplementary Table 1.

We classified the tested subjects into two age categories, adults ( $n=1,355$, sexually mature individuals) and subadults; the latter being comprised by infants ( $n=9$, individuals that had not yet been weaned) and juveniles ( $n=442$, weaned individuals that have not reached sexual maturity). If previous tube task studies assigned age categories to their subjects, we adopted this classification for the individuals concerned. In other cases and for our original data, age classification followed life history data from Harvey and Clutton-Brock (1985). The taxonomy and nomenclature we apply follows Mittermeier, Rylands, and Wilson (2013) with the following exceptions: The recently diverging sister species pairs Cercopithecus diana and C. roloway (Diana and Roloway monkeys) as well as Nomascus leucogenys and $N$. siki (white-cheeked gibbons) are treated here as one respective taxonomic unit and data were pooled to obtain larger sample sizes (species identity of subjects is noted in Suppl. Table 1). Because the hand preference literature on orangutans (Pongo spp.) did not consider the species status of the individuals concerned, we analyzed respective data on the genus level. In other cases, we carefully checked the current taxonomic status of subjects drawn from the literature and tried to avoid the inclusion of interspecific hybrids. This was particularly relevant for data on lab-housed tufted capuchins (Sapajus spp.). If the species or hybrid status of animals was ambiguous, we did not consider them for our analyses (e.g., capuchins in Westergaard and Suomi, 1996).

Although available for testing at most of the institutions we visited, lemurs could not be included into the study. All tested genera (Eulemur, Hapalemur, Propithecus, Varecia), failed to manually remove food mash from the tube, despite eagerly licking it up from the ends. Only a single subject, a female Eulemur rubriventer, succeeded (Suppl. Table 2). White-faced sakis (Pithecia pithecia) and Javan langurs (Trachypithecus auratus) were also reluctant to engage in the task, so that the final sample for these species is smaller than expected from their abundance at the institutions visited. Apart 
from the species considered for analysis, nine individuals belonging to miscellaneous taxa were sampled in the study (data included in Suppl. Table 1).

\section{Experimental procedure and data scoring}

All species were uniformly tested in the established bimanual tube task paradigm (William D. Hopkins, 1995). Due to the pronounced differences in body size between the observed species, PVC tubes of varying length and diameter were employed (Fig. 1). Lion tamarins (Leontopithecus) were presented with small-sized tubes that were $5 \mathrm{~cm}$ long and had an inner diameter of $1 \mathrm{~cm}$. Capuchins and sakis (Sapajus, Pithecia) received $10 \mathrm{~cm} \times 2 \mathrm{~cm}$ medium-sized tubes and all remaining species large tubes measuring $10 \mathrm{~cm} \times 2.5 \mathrm{~cm}$. The tubes were filled with various food incentives, which differed dependent on the nutrition regimes enacted by the respective institutions. Among preferred food items for cercopithecines, gibbons, spider monkeys, and capuchins were oatmeal mixed with banana mash, soaked pellets, and boiled carrots (but note that the latter did not appeal to Cercopithecus and Ateles). Geladas (Theropithecus gelada) exclusively received boiled carrots. Langurs (Semnopithecus, Trachypithecus) and sakis were preferably tested with boiled rice, and tubes for the latter were also stowed with nuts as an additional incentive. Lion tamarins received tubes filled with pure banana mash or commercial tamarin pie. Primates were preferably tested within their social groups. A separation of individuals was only undertaken in exceptional cases when it was necessary to counteract social tension created by the presentation of the tubes. Dependent on the constructional restraints of the enclosures, tubes were either placed into a separated part of the enclosure before the primates could enter or were handed over directly through the wire mesh. In the latter case, the hand that the experimenter used to offer the tube was noted (Suppl. Table 2). To check whether the hand used by the experimenter to offer the tube had an effect on the directional hand preferences of the tested primates, we ran a linear mixed effect model employing a binomial link function. No effect on the recovered hand preferences in the respective sessions was found $(t=-$ 1.31, $\mathrm{SE}=0.02, p=0.191$ ).

The tube tasks were recorded with digital cameras and scored from the video footage. For each subject, we obtained a minimum of 30 bimanual insertions (one hand is holding the tube, the other one is retrieving food; mean: $50.66 \pm 20.98$, range: $30-155$ ) in at least six bouts (uninterrupted manipulation sequences, as defined by Morino et al. (2017); mean: $20.60 \pm 11.13$, range: 6-82). Literature data for individual subjects had to match or exceed these thresholds to be included into the analysis. Unimanual or foot-assisted insertions were not scored and were, whenever possible, also carefully excluded from the literature data. We noted the digit used to extract the food as well as the body posture of the manipulating individual (sitting, crouched bipedal stance, erect bipedal stance, suspended (clinging to wire mesh or other substrates without the hands stabilizing posture, always tail-assisted in spider monkeys)). The vast majority of responses were observed in a sitting position ( $n=22,993 ; 90.6 \%$ ). Due to this imbalance, because posture-related information was mostly unavailable for literature data, and since its influence on manual laterality already received great research attention in the past (Sanford et al., 1984; Westergaard et al., 1998; Blois-Heulin et al., 2007; Laurence et al., 2011), we refrained from including posture effects into our analyses. Nevertheless, for potential future use by other researchers, we decided to include this measure, alongside information on digit use ("N.A." if ambiguous in the respective footage) during manipulation, in Supplementary Table 2. 
Table 1: Composition of the study sample, listing taxonomic identity, sex, age, and origin of subjects. See cited studies for locations of individuals drawn from the literature.

\begin{tabular}{|c|c|c|c|c|c|c|c|c|c|c|}
\hline Family & Species & $\begin{array}{l}\text { \# Subjects } \\
\text { tested }\end{array}$ & $\begin{array}{l}\text { \# Subjects drawn } \\
\text { from literature* }\end{array}$ & \begin{tabular}{|l|l|} 
Total \\
sample
\end{tabular} & \begin{tabular}{|l|} 
\# adult \\
females
\end{tabular} & $\begin{array}{l}\# \text { adult } \\
\text { males }\end{array}$ & $\begin{array}{l}\text { \# subadult } \\
\text { females }\end{array}$ & $\begin{array}{l}\text { \# subadult } \\
\text { males }\end{array}$ & \begin{tabular}{|l|} 
\# unsexed \\
subadults
\end{tabular} & Locations for subjects in this study \\
\hline Atelidae & Ateles fusciceps & 37 & $9^{a}$ & 46 & 30 & 11 & 3 & 2 & 0 & $\begin{array}{l}\text { Berlin (Zoo), Doué-la-Fontaine, Landau, Mulhouse, Munich, } \\
\text { Osnabrück, Wuppertal }\end{array}$ \\
\hline Atelidae & Ateles geoffroyi & 9 & $14^{b}$ & 23 & 12 & 9 & 0 & 2 & 0 & Basel, Karlsruhe \\
\hline Atelidae & Ateles hybridus & 18 & & 18 & 10 & 7 & 0 & 1 & 0 & Doué-la-Fontaine, Erfurt, Frankfurt, Neuwied, Stuttgart \\
\hline Callitrichidae & Leontopithecus chrysomelas & 30 & & 30 & 11 & 16 & 2 & 1 & 0 & $\begin{array}{l}\text { Apeldoorn, Karlsruhe, Magdeburg, Mulhouse, São Paulo, } \\
\text { Stuttgart, Wuppertal }\end{array}$ \\
\hline Callitrichidae & Leontopithecus chrysopygus & 15 & & 15 & 6 & 9 & 0 & 0 & 0 & São Paulo \\
\hline Callitrichidae & Leontopithecus rosalia & 28 & & 28 & 7 & 16 & 0 & 5 & 0 & $\begin{array}{l}\text { Apeldoorn, Basel, Doué-la-Fontaine, Duisburg, Frankfurt, } \\
\text { Heidelberg, } \\
\text { Landau, Magdeburg, Münster, São Paulo }\end{array}$ \\
\hline Cebidae & Saimiri sciureus & & $36^{c}$ & 36 & 14 & 16 & 5 & 1 & 0 & \\
\hline Cebidae & Sapajus apella & & $25^{\mathrm{d}, \mathrm{e}}$ & 25 & 10 & 11 & 0 & 4 & 0 & \\
\hline Cebidae & Sapajus flavius & 3 & $18^{e}$ & 21 & 7 & 9 & 2 & 3 & 0 & São Paulo \\
\hline Cebidae & Sapajus xanthosternos & 16 & $18^{e}$ & 34 & 11 & 19 & 1 & 2 & 1 & Apeldoorn, Magdeburg, Münster, Overloon \\
\hline Cercopithecidae & Cercocebus torquatus & 18 & $13^{f}$ & 31 & 15 & 13 & 1 & 2 & 0 & Apeldoorn, Berlin (Tierpark), Karlsruhe, Münster \\
\hline Cercopithecidae & Cercopithecus diana/roloway & 20 & & 20 & 9 & 7 & 3 & 1 & 0 & $\begin{array}{l}\text { Amsterdam, Berlin (Tierpark), Doué-la-Fontaine, Duisburg, } \\
\text { Heidelberg, Liberec, Mulhouse, Osnabrück }\end{array}$ \\
\hline Cercopithecidae & Cercopithecus neglectus & 12 & $13^{\mathrm{f}, \mathrm{g}}$ & 25 & 8 & 12 & 1 & 4 & 0 & Bekesbourne, Duisburg, Hanover, Overloon \\
\hline Cercopithecidae & Macaca fascicularis & 12 & $8^{\mathrm{h}}$ & 20 & 13 & 7 & 0 & 0 & 0 & Basel, Hamm, Mönchengladbach \\
\hline Cercopithecidae & Macaca nemestrina & 29 & & 29 & 12 & 15 & 0 & 1 & 1 & Arnhem, Bali, Berlin (Tierpark), Gelsenkirchen, Osnabrück \\
\hline Cercopithecidae & Macaca silenus & 35 & & 35 & 16 & 17 & 1 & 1 & 0 & $\begin{array}{l}\text { Apeldoorn, Bekesbourne, Berlin (Zoo), Cologne, Dresden, } \\
\text { Duisburg, Hodenhagen, Rheine }\end{array}$ \\
\hline Cercopithecidae & Macaca sy/vanus & 15 & $9^{i, j}$ & 24 & 11 & 12 & 0 & 1 & 0 & Aachen, Rheine \\
\hline Cercopithecidae & Macaca tonkeana** & & $14^{k}$ & 14 & NA & NA & NA & NA & NA & \\
\hline Cercopithecidae & Mandrillus sphinx & 32 & & 32 & 14 & 7 & 4 & 7 & 0 & $\begin{array}{l}\text { Amsterdam, Berlin (Zoo), Dresden, Hamm, Hodenhagen, } \\
\text { Hodenhagen }\end{array}$ \\
\hline Cercopithecidae & Papio anubis & & $104^{\prime}$ & 104 & NA & NA & NA & NA & NA & \\
\hline Cercopithecidae & Papio hamadryas & 24 & & 24 & 14 & 10 & 0 & 0 & 0 & Cologne, Frankfurt, Krefeld \\
\hline Cercopithecidae & Pygathrix cinerea & & $18^{\mathrm{m}}$ & 18 & 7 & 11 & 0 & 0 & 0 & \\
\hline Cercopithecidae & Rhinopithecus roxellana & & $24^{n}$ & 24 & 8 & 5 & 8 & 3 & 0 & \\
\hline
\end{tabular}




\begin{tabular}{|c|c|c|c|c|c|c|c|c|c|c|}
\hline Cercopithecidae & Semnopithecus entellus & 30 & & 30 & 17 & 7 & 4 & 2 & 0 & Apeldoorn, Berlin (Zoo), Gelsenkirchen, Hanover, Heidelberg \\
\hline Cercopithecidae & Theropithecus gelada & 38 & & 38 & 20 & 11 & 4 & 3 & 0 & $\begin{array}{l}\text { Bekesbourne, Berlin (Tierpark), Magdeburg, Rheine, } \\
\text { Stuttgart }\end{array}$ \\
\hline Cercopithecidae & Trachypithecus auratus & 8 & & 8 & 3 & 0 & 3 & 2 & 0 & Bali, Stuttgart \\
\hline Cercopithecidae & Trachypithecus hatinhensis & & $18^{\mathrm{m}}$ & 18 & 8 & 10 & 0 & 0 & 0 & \\
\hline Hominidae & Gorilla gorilla & & $76^{\circ}$ & 76 & 22 & 18 & 19 & 17 & 0 & \\
\hline Hominidae & Homo sapiens & & $127^{p}$ & 127 & 71 & 56 & 0 & 0 & 0 & \\
\hline Hominidae & Pan paniscus & & $118^{\circ}$ & 118 & 29 & 23 & 35 & 31 & 0 & \\
\hline Hominidae & Pan troglodytes & & $536^{\circ}$ & 536 & 186 & 138 & 110 & 102 & 0 & \\
\hline Hominidae & Pongo sp. & & $47^{\circ}$ & 47 & 17 & 12 & 9 & 9 & 0 & \\
\hline Hylobatidae & Hylobates lar & 16 & $20^{q}, r, s$ & 36 & 14 & 18 & 2 & 2 & 0 & $\begin{array}{l}\text { Berlin (Tierpark), Cologne, Doué-la-Fontaine, Landau, } \\
\text { Stuttgart, } \\
\text { Ulm, Wuppertal }\end{array}$ \\
\hline Hylobatidae & Hylobates moloch & 22 & & 22 & 8 & 5 & 4 & 5 & 0 & Bekesbourne, Lympne, Munich \\
\hline Hylobatidae & Nomascus gabriellae & 6 & $4^{r}$ & 10 & 5 & 3 & 0 & 2 & 0 & Arnhem, Doué-la-Fontaine \\
\hline Hylobatidae & Nomascus leucogenys /siki & 7 & $19 q, r, t$ & 26 & 15 & 7 & 1 & 3 & 0 & Apeldoorn, Frankfurt, Osnabrück \\
\hline Hylobatidae & Symphalangus syndactylus & 14 & $17^{q, r}$, & 31 & 12 & 11 & 4 & 4 & 0 & $\begin{array}{l}\text { Arnhem, Bekesbourne, Berlin (Zoo), Dortmund, Doué-la- } \\
\text { Fontaine, } \\
\text { Munich, Arnhem, Hodenhagen, Osnabrück }\end{array}$ \\
\hline Pitheciidae & Pithecia pithecia & 7 & & 7 & 4 & 3 & 0 & 0 & 0 & Basel, Dresden, Krefeld \\
\hline \multicolumn{2}{|l|}{ Total*** } & 501 & 1305 & 1806 & 676 & 561 & 226 & 223 & 2 & \\
\hline
\end{tabular}

* Fulfilling our criteria

** Ages unknown, sex derived from given names

*** Not including $M$. tonkeana and $P$. anubis in sex and age specific

categories

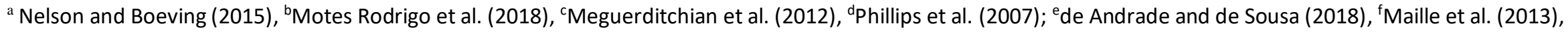

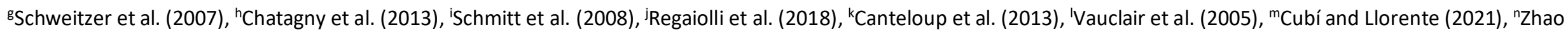
et al. (2012), ${ }^{\circ}$ Hopkins et al. (2011), ${ }^{\mathrm{P} C o c h e t}$ and Vauclair (2012), ${ }^{\mathrm{q}}$ Morino et al. (2017), ${ }^{\mathrm{r} C}$ aspar et al. (2018), ${ }^{\mathrm{s} S p o e l s t r a}$ (2021), ${ }^{\mathrm{t}} \mathrm{Fan}$ et al. (2017). 


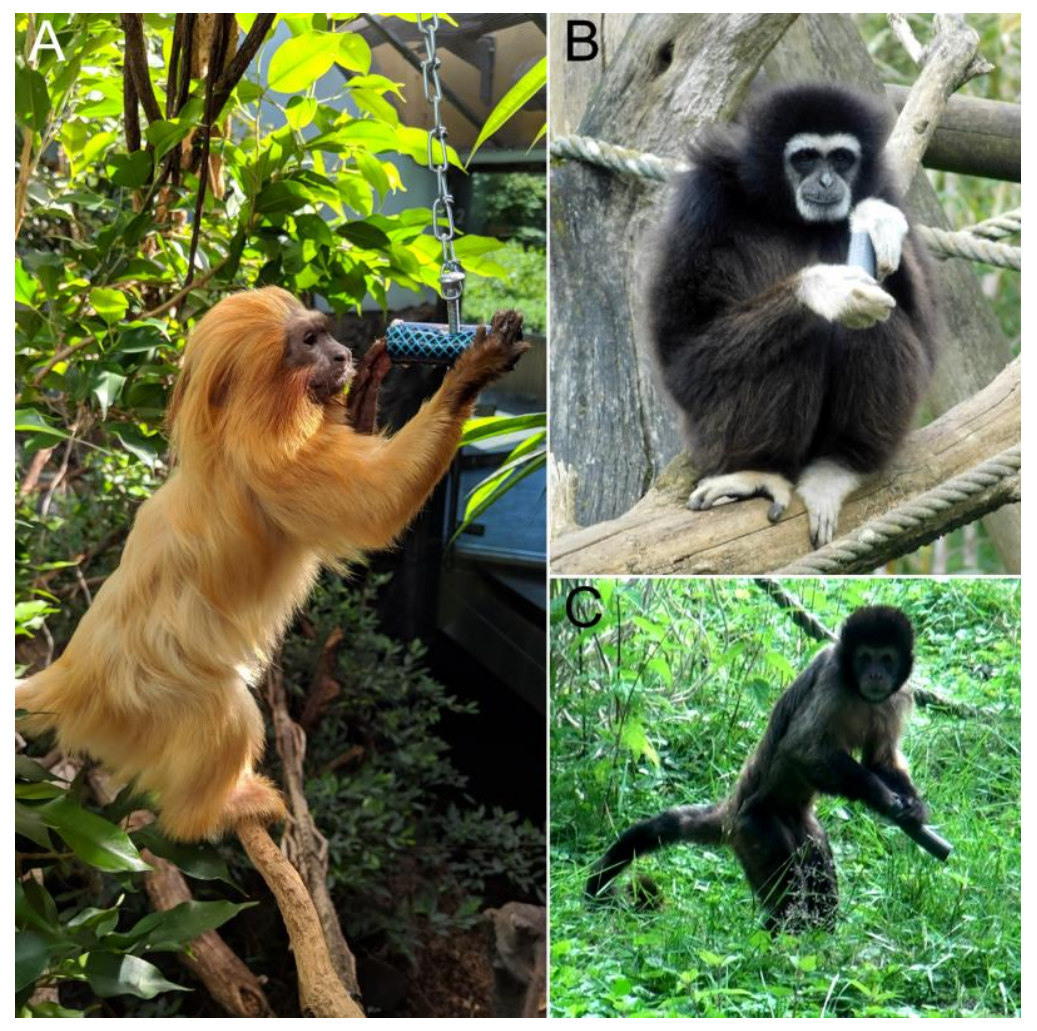

Figure 1: Various anthropoid primates engaging in the tube task. A: Golden lion tamarin (Leontopithecus rosalia) manipulating a small tube at Zoo Frankfurt, Germany. B: White-handed gibbon (Hylobates lar) handling a large tube at Bioparc de Doué-la-Fontaine, France. Note that the thumb is used to probe into the tube, an insertion pattern characteristic of gibbons. C: Yellowbreasted capuchin (Sapajus xanthosternos) engaging in the task with a medium-sized tube while adopting an erect bipedal stance at ZooParc Overloon, the Netherlands. Photographs by Kai R. Caspar.

\section{Statistics}

Data were analyzed in R (R Core Team, 2020). Preferably, analyses were performed on insertion data (also called frequencies) instead of manipulations bouts to approximate laterality. Unfortunately, not all available tube task studies provided insertion data (Maille et al., 2013; Spoelstra, 2021), so that in the final dataset, estimates of manual lateralization based on insertions and bouts had to be mixed for three species (Cercocebus torquatus, Cercopithecus neglectus, and Hylobates lar). However, since previous work demonstrated that hand preferences derived from bouts and insertions are highly correlated and non-conflicting, we do not consider this a confounding factor for our analysis (Hopkins et al., 2001; Hopkins, 2013a).

For quantifying lateralized responses on the individual level, we calculated handedness indices (HI) for all subjects as well as the corresponding binomial $z$ scores to allow grouping into hand preference categories. $\mathrm{HI}$ is a descriptive index that can range from - 1 (all manipulations left-handed) to 1 (all right-handed) and is calculated via the formula $\mathrm{HI}=(\mathrm{R}-\mathrm{L}) /(\mathrm{R}+\mathrm{L})$. The $\mathrm{z}$ score, on the other hand, indicates whether there is a statistically significant bias in hand use. Following established criteria (Hopkins, 2013a), we rated subjects with z score values higher than 1.96 as right-handed, those with values lower than -1.96 as left-handed, and the remaining ones as ambipreferent. We use the term "ambipreferent" here instead of "ambidextrous" or "ambiguously handed" to indicate a lack of preferences, because the latter two expressions have clear non-synonymous definitions when 
applied to human, but are not consistently used in the non-human primate literature (Hopkins et al., 2013). At the species level, we used the mean $\mathrm{HI}$ of subjects as a measure of lateralization direction and the mean of absolute $\mathrm{HI}$ values (MeanAbsHI) as a measure of strength. We employed ordinary least squares regression to check for a species-level correlation between these measures of hand preference.

We applied one-sample t-tests to each species sample encompassing data for at least 15 individuals to check whether $\mathrm{HI}$ distributions were significantly skewed at the population-level. Additionally, the chi-square goodness-of-fit test was employed to test if the numbers of left- and right-handers as well as ambipreferent individuals differed from a baseline distribution. Earlier studies performed the goodness-of-fit test against the null hypothesis of a chance distribution of the three hand preference categories (Vauclair et al., 2005). Due to our large species sample, we could adopt a different approach: For each of the three major clades studied (Cercopithecoidea, Hominoidea, and Platyrrhini), we calculated the mean frequencies of individuals falling into these three hand preference categories as a baseline. Distributions for each species were than compared to this cladespecific average. For the Hominoidea, we excluded humans for the calculation of the baseline, because their evidently extreme right-hand bias would have otherwise skewed the results. Within the remaining dataset, two species stood out due to vastly greater sample sizes than provided for others from their respective clades: chimpanzees (Pan troglodytes, $n=536$ ) and olive baboons (Papio anubis, $n=104)$. To prevent these taxa to skew the comparisons, we restricted their respective sample sizes to the numbers of individuals in the second-largest species sample for their respective clade. This resulted in samples of $n=118$ chimpanzees and $n=38$ olive baboons. The relative percentages of the three handedness categories among chimpanzees and olive baboons after the sample size reduction corresponded to those in the original sample. Bonferroni correction was employed to address multiple testing.

We employed the phytools package version 0.7-70 (Revell, 2012) to visualize evolutionary patterns, quantify phylogenetic signals (by employing Pagel's $\lambda$ - Freckleton et al., 2002) and to calculate maximum likelihood ancestral state estimates (Suppl. Table 3), each separately for direction and strength of lateralization. Time-calibrated primate phylogenies were derived from the 10kTrees website (Arnold et al., 2010). Three species in our study were not included in the respective database, Ateles hybridus, Sapajus flavius, and Trachypithecus hatinhensis. We therefore replaced $A$. hybridus and $T$. hatinhensis in the tree with respective sister taxa, namely $A$. belzebuth and $T$. francoisi (Morales-Jimenez et al., 2015; Roos et al., 2019), for which data were provided. This way the topology and branch lengths of the tree could be kept equal to a model which would have included the actual species we studied. The same could not be done for $S$. flavius, so that it was amended manually in the respective trees by relying on divergence dating from Lima et al. (2018).

We computed phylogenetic generalized least squares (PGLS) regression models to test the effects of different biological variables on hand preferences while addressing phylogeny (correlation structure: Pagel's $\lambda$; model fit: maximum likelihood). The R packages ape (Paradis, 2019), nlme (Pinheiro, 2020), and MuMIn (Barton, 2020) were used for model creation and evaluation. We used multi-model inference to test how well hypothesis-derived predictors could explain $\mathrm{HI}$ measures on the species level. Predictor-based models were ranked against a NULL model to estimate their explanatory power and identify the best-performing one (dredge function in MuMIn). Second order Akaike's information criteria $(\mathrm{AICC})$ and respective Akaike weights were used to evaluate model components. We relied on the conditional model average to assess effects of individual predictors. We selected the following variables as model predictors to address established hypotheses on the evolution on primate hand preferences: Ecology (terrestrial vs. arboreal), occurrence of habitual tool use (binarily coded), and endocranial volume (numeric) of females (see Suppl. Table 4 for predictor data and 
respective references). We ran the models on the species means for $\mathrm{HI}$ and $\mathrm{AbsHI}$, respectively, resulting in two separate analyses for direction and strength of population-level laterality. All species $(n=38)$ were included into the strength (AbsHI) analysis. For direction, we only considered species for which we had at least 15 sampled individuals, resulting in a more restricted sample $(n=34)$. Since humans are both extreme outliers in regard to absolute brain size and hand preference direction, we decided to compute a second direction model to identify potential biases that might derive from their inclusion. Thus, this second model on hand preference direction encompassed a species sample of $n=33$.

Finally, we employed Wilcoxon rank sum tests to check whether individual $\mathrm{HI}$ and $\mathrm{AbsHI}$ were influenced by affiliation to the three superordinate taxa studied, age, and sex (excluding unsexed individuals; $n=2$ ). Effects of the latter were checked for both the total sample and separately for each superordinate group. When appropriate, Bonferroni correction was applied to address for multiple testing. Due to their highly derived handedness patterns, we again excluded humans from these analyses to avoid skewing the results. To further avoid bias, we also removed chimpanzees from the models, since they are vastly overrepresented in our sample (31\% of total individuals and $47 \%$ of all subadults). Finally, as no individual data on olive baboons and age data on Tonkean macaques (Macaca tonkeana) were available, these species were not featured in these analyses as well, leaving us with a sample of $n=1,023$ individuals.

\section{Results}

Lateralization strength (MeanAbsHI) but not direction (MeanHI) displays a strong phylogenetic signal among anthropoids (Figure 2). Accordingly, MeanAbsHI $(\lambda=0.94)$ varied substantially between lineages but was largely stable within groups of closely related taxa. MeanHI on the other hand, showed random fluctuations $(\lambda<0.001)$. We found no correlation between these two measures of hand preference $\left(R^{2}=-0.028 ; F=0.097 ; p=0.758\right)$. Species-level distributions of hand preferences are visualized in Figure 3 and summarized in Table 2.

Ancestral hand preference strength was modelled to have been similarly moderate in the stem lineages of hominoids ( $\mathrm{AbsHI}=0.605)$ and cercopithecoids $(\mathrm{AbsHI}=0.624)$, while it was inferred to be higher in the ancestral platyrrhines (AbsHI $=0.738$; Fig. 2, Suppl. Tab. 3). We found hand preference strength to be particularly weak among baboons and their relatives (Papionina) and to be least expressed in the gelada (Theropithecus gelada $-\mathrm{MeanAbsHI}=0.257$ ). The strongest preferences were found in humans (MeanAbsHI $=0.943$ ), langurs of the genus Trachypithecus (MeanAbsHI $=0.868$ ), and spider monkeys (Ateles spp.- MeanAbsHI = 0.831). In consequence, these taxa included only very few, if any, ambipreferent individuals. The South Asian colobines Rhinopithecus and Trachypithecus were the only genera in which no ambipreferent individuals were found. Direction of manual lateralization was far more uniform across the anthropoid radiation than strength (Fig. 2; Suppl. Tab. 3). No species approached the extreme direction bias of humans, and only 2 of 37 non-human species exhibited a significant population-level bias after correcting for multiple testing, namely gorillas and chimpanzees. Thus, such biases were restricted to the African ape lineage. After correcting for multiple testing, intraspecific frequencies of ambipreferent individuals, right-, and left-handers differed significantly from the superordinate taxon mean in just two cases, namely for humans and chimpanzees, which are both right-handed at the population-level (Tab. 2). For intrageneric patterns, again only two such taxa were found. These encompassed humans and lion tamarins, in which ambipreferent individuals occur more frequently than in the other sampled platyrrhines. 


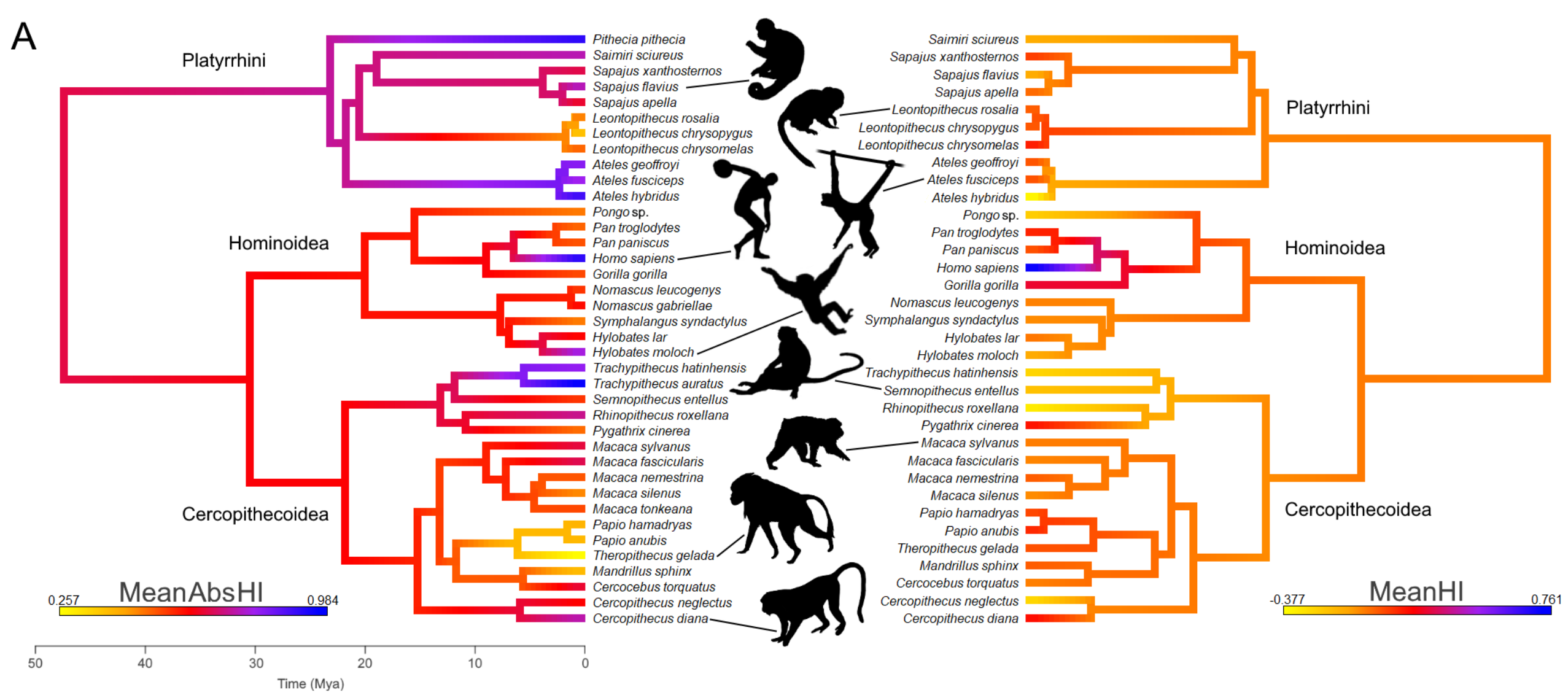

Figure 2: A color-coded phylogeny of hand preferences in anthropoid primates. The strength (A) and direction (B) of laterality, expressed by the mean absolute handedness index (MeanAbsHI) and the mean handedness index (MeanHI), respectively, calculated for each species and inferred for each tree node by maximum likelihood estimates. Silhouettes by Kai R. Caspar, except Ateles (by Yan Wong, public domain) and Homo (public domain). 


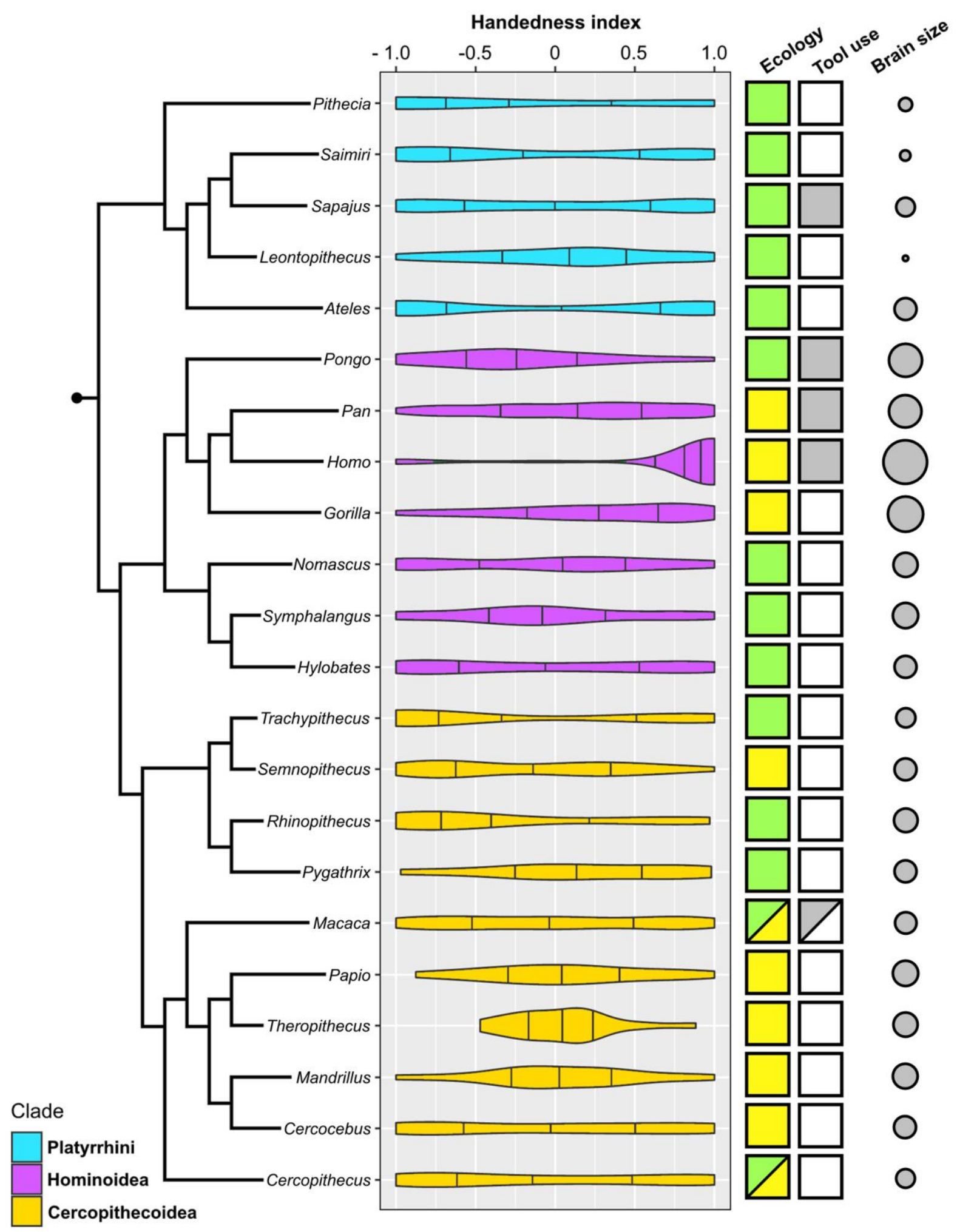

Figure 3: Violin plots of hand preference distribution in 22 genera of anthropoid primates and the genus-specific expression of three potential biological correlates (ecology, tool use, and absolute brain size). Attributions only apply to the species that represent the respective genus within our sample. P. anubis is not included in the Papio visualization. Color coding: Ecology - green: arboreal, yellow: terrestrial; Habitual tool use - grey: present; white: absent. Brain size is visualized here as the log-transformed genus average of female endocranial volume. 
Table 2: Hand preferences of anthropoid species as recovered by the tube task. * Results remain significant after Bonferroni correction. ${ }^{* *}$ Results for Papio anubis were taken from Vauclair et al. (2005), data could not be reanalyzed here.

\begin{tabular}{|c|c|c|c|c|c|c|c|c|c|c|c|}
\hline Species & $n$ & \# left (\%) & \# right (\%) & $\begin{array}{l}\text { \# ambipreferent } \\
\text { (\%) }\end{array}$ & MeanHI & MeanAbsHI & $\begin{array}{l}\text { Species } \\
\text { direction bias } \\
\text { (HI), } p \text { value }\end{array}$ & $\begin{array}{l}\text { Species L/R/A } \\
\text { distribution, } p \\
\text { value }\end{array}$ & $n_{\text {Genus }}$ & $\begin{array}{l}\text { Genus } \\
\text { direction bias } \\
\text { (HI), } p \text { value }\end{array}$ & $\begin{array}{l}\text { Genus } \mathrm{L} / \mathrm{R} / \mathrm{A} \\
\text { distribution, } \\
p \text { value }\end{array}$ \\
\hline Ateles fusciceps & 46 & $20(43.5)$ & $22(47.8)$ & $4(8.7)$ & 0.063 & 0.798 & 0.618 & 0.278 & 87 & 0.759 & 0.069 \\
\hline Ateles geoffroyi & 23 & $10(43.5)$ & $11(47.8)$ & $2(8.7)$ & 0.061 & 0.829 & 0.748 & 0.527 & & & \\
\hline Ateles hybridus & 18 & $13(72.2)$ & $5(27.8)$ & 0 & -0.377 & 0.917 & 0.086 & 0.043 & & & \\
\hline Cercocebus torquatus & 31 & $13(41.9)$ & $11(35.5)$ & $7(22.6)$ & -0.029 & 0.665 & 0.832 & 0.995 & 31 & 0.832 & 0.995 \\
\hline Cercopithecus diana & 20 & $7(35)$ & $9(45)$ & $4(20)$ & 0.178 & 0.755 & 0.339 & 0.662 & 45 & 0.572 & 0.250 \\
\hline Cercopithecus neglectus & 25 & $17(68)$ & $6(24)$ & $2(8)$ & -0.258 & 0.621 & 0.061 & 0.032 & & & \\
\hline Gorilla gorilla & 76 & $17(22.4)$ & 41 (53.9) & $18(23.7)$ & 0.248 & 0.541 & $<0.001 *$ & 0.022 & 76 & $<0.001^{*}$ & 0.022 \\
\hline Homo sapiens & 127 & $12(9.5)$ & $111(87.4)$ & $4(3.1)$ & 0.761 & 0.943 & $<0.001 *$ & $<0.001 *$ & 127 & $<0.001 *$ & $<0.001 *$ \\
\hline Hylobates lar & 36 & $17(47.2)$ & $16(44.5)$ & $3(8.3)$ & -0.011 & 0.614 & 0.924 & 0.184 & 58 & 0.612 & 0.106 \\
\hline Hylobates moloch & 22 & $11(50)$ & $8(36.4)$ & $3(13.6)$ & -0.115 & 0.799 & 0.540 & 0.464 & & & \\
\hline Leontopithecus chrysomelas & 30 & $11(36.7)$ & $11(36.7)$ & $8(26.6)$ & 0.151 & 0.514 & 0.149 & 0.261 & 73 & 0.232 & $0.001 *$ \\
\hline Leontopithecus chrysopygus & 15 & $4(26.7)$ & $5(33.3)$ & $6(40)$ & 0.039 & 0.350 & 0.759 & 0.035 & & & \\
\hline Leontopithecus rosalia & 28 & $11(39.3)$ & $8(28.6)$ & $9(32.1)$ & 0.022 & 0.502 & 0.849 & 0.062 & & & \\
\hline Macaca fascicularis & 20 & $9(45)$ & $9(45)$ & $2(10)$ & -0.036 & 0.684 & 0.601 & 0.399 & 102 & 0.758 & 0.926 \\
\hline Macaca nemestrina & 29 & $10(34.5)$ & $11(37.9)$ & $8(27.6)$ & 0.035 & 0.527 & 0.797 & 0.628 & & & \\
\hline Macaca silenus & 35 & $16(45.7)$ & $11(31.4)$ & $8(22.9)$ & -0.051 & 0.467 & 0.622 & 0.883 & & & \\
\hline Macaca sylvanus & 24 & $10(41.7)$ & $10(41.7)$ & $4(16.6)$ & -0.025 & 0.670 & 0.917 & 0.752 & & & \\
\hline Macaca tonkeana & 14 & $5(35.7)$ & $3(21.4)$ & $6(42.9)$ & -0.057 & 0.543 & NA & 0.154 & & & \\
\hline Mandrillus sphinx & 32 & $7(21.9)$ & $11(34.4)$ & $14(43.7)$ & 0.034 & 0.389 & 0.448 & 0.006 & 32 & 0.448 & 0.006 \\
\hline Nomascus gabriellae & 10 & $5(50)$ & $2(20)$ & $3(30)$ & -0.173 & 0.618 & NA & 0.353 & 36 & 0.381 & 0.674 \\
\hline Nomascus leucogenys & 26 & $9(34.6)$ & $11(42.3)$ & $6(23.1)$ & -0.031 & 0.555 & 0.593 & 0.913 & & & \\
\hline Pan paniscus & 118 & $50(42.4)$ & $51(43.2)$ & $17(14.4)$ & 0.044 & 0.529 & 0.431 & 0.272 & 654 & $<0.001^{*}$ & 0.002 \\
\hline Pan troglodytes & 536 & 155 (28.9) & $266(49.6)$ & 115 (21.5) & 0.133 & 0.507 & 0.013 & $<0.001^{*}$ & & & \\
\hline Papio anubis** & 104 & $33(31.7)$ & $52(50)$ & $19(18.3)$ & 0.130 & 0.400 & $<0.05$ & 0.008 & 128 & NA & 0.009 \\
\hline
\end{tabular}




\begin{tabular}{|c|c|c|c|c|c|c|c|c|c|c|c|}
\hline Papio hamadryas & 24 & $7(29.2)$ & $9(37.5)$ & $8(33.4)$ & 0.066 & 0.408 & 0.534 & 0.289 & & & \\
\hline Pithecia pithecia & 7 & $4(57.1)$ & $1(14.3)$ & $2(28.6)$ & -0.385 & 0.934 & NA & 0.370 & 7 & NA & 0.370 \\
\hline Pongo sp. & 47 & $27(57.5)$ & $9(19.1)$ & $11(23.4)$ & -0.225 & 0.487 & 0.006 & 0.004 & 47 & 0.006 & 0.004 \\
\hline Pygathrix cinerea & 18 & $6(33.3)$ & $9(50)$ & $3(16.7)$ & 0.165 & 0.499 & 0.268 & 0.434 & 18 & 0.268 & 0.434 \\
\hline Rhinopithecus roxellana & 24 & $17(70.8)$ & $7(29.2)$ & 0 & -0.319 & 0.729 & 0.040 & 0.007 & 24 & 0.040 & 0.007 \\
\hline Saimiri sciureus & 36 & $21(58.4)$ & 14 (38.9) & $1(2.7)$ & -0.119 & 0.757 & 0.382 & 0.073 & 36 & 0.382 & 0.073 \\
\hline Sapajus apella & 25 & $11(44)$ & $10(40)$ & $4(16)$ & 0.016 & 0.651 & 0.917 & 0.989 & 80 & 0.922 & 0.5903 \\
\hline Sapajus flavius & 21 & $9(42.9)$ & $8(38.1)$ & $4(19)$ & -0.130 & 0.769 & 0.495 & 0.924 & & & \\
\hline Sapajus xanthosternos & 34 & $15(44.1)$ & $14(41.2)$ & $5(14.7)$ & 0.089 & 0.677 & 0.492 & 0.950 & & & \\
\hline Semnopithecus entellus & 30 & $18(60 \%)$ & $7(23.4)$ & $5(16.6)$ & -0.184 & 0.560 & 0.110 & 0.155 & 30 & 0.110 & 0.155 \\
\hline Symphalangus syndactylus & 31 & $12(38.7)$ & $8(25.8)$ & $11(35.5)$ & -0.048 & 0.482 & 0.665 & 0.058 & 31 & 0.665 & 0.058 \\
\hline Theropithecus gelada & 38 & $11(28.95)$ & $11(28.95)$ & $16(42.1)$ & 0.053 & 0.257 & 0.326 & 0.010 & 38 & 0.326 & 0.010 \\
\hline Trachypithecus auratus & 8 & $6(75)$ & $2(25)$ & 0 & -0.256 & 0.984 & & 0.138 & 26 & 0.153 & 0.012 \\
\hline Trachypithecus hatinhensis & 18 & $11(61.1)$ & $7(38.9)$ & 0 & -0.248 & 0.817 & 0.219 & 0.066 & & & \\
\hline
\end{tabular}


Our selected predictors for PGLS models performed poorly in explaining expression patterns of hand preference strength and direction in anthropoids (Tab. 3, Fig. 4). For lateralization direction, we found no significant effects for any of our predictors $(p>0.1$; Tab. 3A, B). This was true regardless of whether humans were featured in the analyses or not. When humans were included (Tab. 4A), the model components brain size and ecology only slightly outperformed the null model. When humans were not considered in the analysis, it was the null model that performed best (Tab. 4B), indicating a bias derived from the extreme right handedness found in our species. Thus, habitual tool use, ecology (terrestrial vs arboreal), and absolute brain size clearly do not influence the direction of lateralization among anthropoids in general. A very different pattern was found for lateralization strength. Here, a significant negative effect of a terrestrial lifestyle was found ( $p=0.009$; see Tab. $3 C)$. In line with that, models including the component ecology consistently outperformed the null model, which was not the case for those including only tool use and brain size (Tab. 4C). Thus, terrestrial anthropoids show weaker hand preferences than arboreal ones while there is no correlation with brain size or habitual tool use.

At the individual level, Wilcoxon rank sum tests showed that neither age, nor sex or affiliation to the three studied superordinate primate taxa had an influence on lateralization direction $(p>0.05)$. The same was true for effects of sex on $\mathrm{HI}$ within the three clades $(p>0.26)$. Again, results on lateralization strength contrasted with the patterns recovered for direction. We found a significant effect of age on individual lateralization strength, with adult anthropoids (MeanAbsHI $=0.614$ ) displaying significantly stronger hand preferences than subadults (MeanAbsHI $=0.531 ; p<0.001$ ). Besides that, platyrrhines show significantly stronger hand preference (MeanAbsHI $=0.696$ ) than both the Cercopithecoidea (MeanAbsHI $=0.561$ ) and the Hominoidea (MeanAbsHI $=0.551$ (but note exclusion of humans, chimpanzees, and olive baboons here); $p<0.001$ for both comparisons), while the latter two clades did not differ significantly in this respect $(p=1)$. Within platyrrhines, males (MeanAbsHI $=0.644$ ) showed significantly weaker hand preferences than females (MeanAbsHI = $0.752 ; p=0.001$ ). Sex-specific hand preference patterns were neither found for the other taxa, nor for the complete sample $(p>0.24)$.

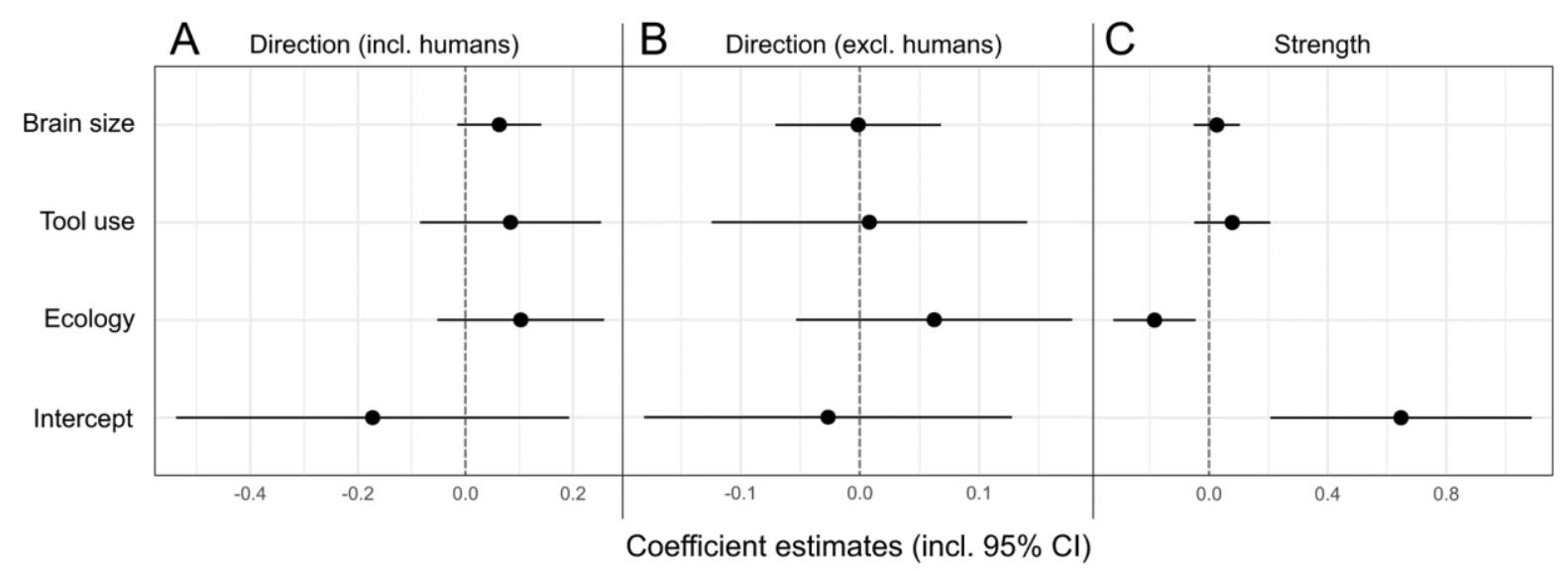

Figure 4: Visualization of PGLS coefficient estimates (including $95 \%$ confidence intervals) for the influence of brain size, tool use, and ecology on lateralization direction (A, B) as well as strength $(C)$ in anthropoid primates. Two models for lateralization direction were computed, one including $(A)$ the other one excluding humans (B). 
Table 3: Conditional average of PGLS model coefficients for lateralization strength and direction in anthropoid primate species.

\begin{tabular}{|l|l|l|l|}
\hline \multicolumn{4}{|l|}{ A: Conditional PGLS model average for lateralization direction, including humans } \\
\hline Predictor & Estimate & Std. Error & $\boldsymbol{p}$ value \\
\hline Ecology (Terrestrial lifestyle) & 0.103 & 0.076 & 0.194 \\
Tool use (present) & 0.084 & 0.083 & 0.329 \\
Log $_{10}$ brain size & 0.063 & 0.038 & 0.114 \\
\hline B: Conditional PGLS model average for lateralization direction, & excluding humans \\
\hline Predictor & Estimate & Std. Error & $\boldsymbol{p}$ value \\
\hline Ecology (Terrestrial lifestyle) & 0.062 & 0.057 & 0.292 \\
Tool use (present) & 0.008 & 0.065 & 0.907 \\
Log $_{10}$ brain size & -0.002 & 0.034 & 0.966 \\
\hline C: Conditional PGLS model average for lateralization strength & \multicolumn{3}{|l}{} \\
\hline Predictor & Estimate & Std. Error & $\boldsymbol{p}$ value \\
\hline Ecology (Terrestrial lifestyle) & -0.184 & 0.068 & $\mathbf{0 . 0 0 9}$ \\
Tool use (present) & 0.078 & 0.063 & 0.232 \\
Log $_{10}$ brain size & 0.026 & 0.039 & 0.511 \\
\hline
\end{tabular}

Table 4: Results of PGLS model averaging for lateralization direction (considering the inclusion and exclusion of humans) and strength. Null models are shown in italics. Df. = Degrees of freedom. AICC = Second order Akaike information criterion.

\begin{tabular}{|c|c|c|c|c|}
\hline A: PGLS model for lateralization direction, including humans \\
\hline Components & Df. & AICc & $\Delta$ AICc & Weight \\
\hline Brain size & 3 & -12.06 & 0 & 0.28 \\
Ecology & 3 & -10.99 & 1.06 & 0.16 \\
Brain size, ecology & 4 & -10.31 & 1.74 & 0.12 \\
(NULL) & 2 & -10.25 & 1.80 & 0.11 \\
Ecology, tool use & 4 & -10.22 & 1.84 & 0.11 \\
Brain size, tool use & 4 & -9.96 & 2.10 & 0.10 \\
Tool use & 3 & -9.60 & 2.46 & 0.08 \\
Ecology, tool use, brain size & 5 & -8.35 & 3.71 & 0.04 \\
\hline B: PGLS model for lateralization direction, excluding humans & & \\
\hline Components & Df. & AICc & $\Delta$ & Weight \\
\hline (NULL) & 2 & -29.01 & 0 & 0.39 \\
Ecology & 3 & -27.84 & 1.17 & 0.21 \\
Tool use & 3 & -26.61 & 2.40 & 0.12 \\
Brain size & 3 & -26.60 & 2.42 & 0.11 \\
Ecology, tool use & 4 & -25.39 & 3.63 & 0.06 \\
Ecology, brain size & 4 & -25.27 & 3.75 & 0.06 \\
\hline & & & & \\
\hline & 3 & & \\
\hline
\end{tabular}




\begin{tabular}{|c|c|c|c|c|}
\hline Tool use, brain size & 4 & -24.02 & 5.00 & 0.03 \\
\hline Ecology, tool use, brain size & 5 & -22.68 & 6.33 & 0.02 \\
\hline \multicolumn{5}{|c|}{ C: PGLS model for lateralization strength } \\
\hline Components & Df. & AICc & $\Delta \mathrm{AICC}$ & Weight \\
\hline Ecology & 3 & -4.73 & 0 & 0.38 \\
\hline Ecology, tool use & 4 & -4.09 & 0.64 & 0.27 \\
\hline Ecology, brain size & 4 & -3.23 & 1.50 & 0.18 \\
\hline Ecology, tool use, brain size & 5 & -1.70 & 3.02 & 0.08 \\
\hline (NULL) & 2 & -0.20 & 4.53 & 0.04 \\
\hline Tool use & 3 & 0.81 & 5.54 & 0.02 \\
\hline Brain size & 3 & 2.12 & 6.85 & 0.01 \\
\hline Tool use, brain size & 4 & 2.84 & 7.57 & 0.01 \\
\hline
\end{tabular}

\section{Discussion}

\section{General}

Our study provides the first quantitative phylogenetic perspectives on hand preferences in monkeys, apes, and humans. While population-level lateralization strength is highly varied among anthropoid primates and often distinctly expressed in specific lineages, direction fluctuates randomly and appears comparatively uniform. Indeed, significant population-level biases are notably rare. After expanding the sample size for some species in which such biases haven been previously reported based on the tube task (siamang - Morino et al., 2017; de Brazza's monkey - Schweitzer et al., 2007), we failed to replicate significant deviations from a chance distribution (even if not correcting for multiple testing). The only taxon in which significant hand use biases occur frequently, is constituted by the great apes and humans. Nevertheless, since sample sizes for species in this group are consistently and conspicuously large, statistical analyses performed on them (in particular the frequently applied one-sample t-test) will have higher power compared to tests done on taxa represented by a smaller number of individuals. It is therefore premature to assume that hominids display qualitatively different population-level lateralization patterns than other primates. Looking at the population-level frequencies of right-handed, left-handed, and ambipreferent individuals, cercopithecoids such as the golden snub-nosed monkey (70.8 \% left-handers, $0 \%$ ambipreferents, MeanHI: -0.319) and de Brazza's monkey (68\% left-handers, $8 \%$ ambipreferents, MeanHI: -0.258 ) approach a human-like skew more than any great ape species does, albeit in the contrary direction to lateralization in our species (approximated herein as encompassing 87.3\% right-handers, $3.1 \%$ ambipreferents, MeanHI: 0.761). Whether the hand preference patterns recovered for these monkeys are indeed representative needs to be clarified in future studies, which should expand the available samples.

The fact that population-level hand preference fluctuates randomly among anthropoids, suggests that there are no general directional selective pressures acting on this trait, different from what pertaining hypotheses predict (see below). On the other hand, population-level lateralization strength is more variable but consistent among closely related taxa, thus exhibiting a strong phylogenetic signal. Our finding that hand preference strength is generally weaker in juveniles compared to adults replicates results from several studies relying on smaller sample sizes (e.g., Westergaard \& Suomi, 1996; Zhao et al., 2012). PGLS modelling demonstrated a significant negative effect of a terrestrial lifestyle on hand preference strength, indicating an influence of ecology. In line with this, the exclusively arboreal platyrrhines were found to be significantly stronger lateralized 
than cercopithecoids and hominoids. It appears intuitive that terrestrial taxa tend to be less lateralized than arboreal ones, since the latter often need to flexibly stabilize their body in the canopy, for instance while foraging. Accordingly, one hand will be preferably used to provide such support, but whether the left or the right one adopts this function seems to be arbitrary. The fact that these lateralization tendencies were found in zoo-housed primates that often adopt locomotor regimes very different from their wild conspecifics (e.g., captive spider monkeys and gibbons spend considerable amounts of time moving and feeding on the ground), suggest a significant innate component to these patterns. However, within ecologically uniform groups, the variability of hand preference strength can still be notable, at times even among closely related taxa (compare e.g., Javan gibbon and siamang), pointing at yet unidentified biological influences being at play. Given the great variability of lateralization strength among anthropoids and its ties to phylogeny as well as ecology, this aspect of manual lateralization and its evolution should receive more research attention in the future. In the past, most work and evolutionary considerations regarding primate handedness have instead focused on lateralization direction, surely for anthropocentric reasons. As we attempt to show here however, the explanatory power of these in parts very long-lived conjectures appears to be remarkably limited.

\section{Testing prevalent hypotheses}

Our data does not support any of the tested hypotheses on hand preference evolution in primates. The traditional postural origins hypothesis $(\mathrm{POH})$ assumes right-hand tendencies for manipulation across anthropoid taxa. However, we found that anthropoid population-level lateralization is in most cases not notably shifted into either direction, with a slight majority of species displaying a weak lefthand bias ( 20 of 38 species). The novel $\mathrm{POH}$ assumes that terrestrial primates tend to be righthanded, while arboreal ones tend to be left-handed, a claim left unsupported by our PGLS models for lateralization direction. It is important to note that the recovered correlation between arboreality and hand preference strength does not support any version of the $\mathrm{POH}$, as they focus exclusively on lateralization direction. Furthermore, the evolutionary scenario proposed by the $\mathrm{POH}$ is outdated and should not be perpetuated without explicitly stating its shortcomings. According to the POH, smallbodied bushbabies (genus Galago) are suitable models for early primates, since they would be "the most direct descendants of the earliest forms" (MacNeilage, 2007). Because contemporary studies suggested a left-hand bias for prey grasping in bushbabies, such a pattern was also assumed for primate ancestors in the paper that introduced the original POH (MacNeilage et al., 1987). However, these assumptions have always been speculative and become problematic in light of more recent data. First, there is no convincing evidence for preferably left-handed grasping in the genus Galago, or other galagids, anymore (Papademetriou et al., 2005). Second, bushbabies represent a remarkably derived radiation of strepsirrhines (Tab Rasmussen \& Nekaris, 1998) and are thus no suitable ecological models for the common ancestor of modern primates. Current evidence suggests that both the earliest primates and the ancestors of the anthropoid clade studied herein, were omnivorous arboreal quadrupeds with moderate leaping ability (Silcox et al., 2009; Gebo, 2011; Sussman, Tab Rasmussen, \& Raven, 2013) and possibly diurnal habits (Tan et al., 2005; Ankel-Simons $\&$ Rasmussen, 2008). Thus, they were extremely different from extant galagos.

Our results suggest that the common ancestor of anthropoids did not display a notable populationlevel hand preference for manipulation, nor that such biases are common among extant monkeys and apes. While lemurs (different from galagos) indeed appear to show a consistent left-hand preference for unimanual reaching, this pattern is not recovered in bimanual tasks (Papademetriou et al., 2005; Regaiolli et al., 2016; Batist \& Mayhew, 2020), again contradicting the POH (MacNeilage, 2007). Therefore, both the unsupported evolutionary scenario proposed by the $\mathrm{POH}$ and the lack of 
empirical evidence for its predictions lead us to dismiss it as a relevant idea in the current discourse on the evolution of primate manual lateralization.

We also found no effects of tool use on neither direction, nor strength of lateralization although our sample represented all primate lineages that include habitual tool users (Musgrave \& Sanz, 2018). Surprisingly, we also did not recover notable influences of absolute brain size on hand preferences. An effect on lateralization strength was expected both on theoretical considerations (Ringo et al., 1994) and empirical evidence from studies investigating intra- and interspecific covariation of brain size and overall cortical lateralization (Kong et al., 2018; Ardesch et al., 2021). Why do anthropoid hand preferences not conform to these predictions? We cannot provide a satisfying answer to this question. It is possible that the effects of increased overall brain lateralization on hand preference expression turn out to be unexpectedly weak and are masked by yet unidentified neurologic factors.

All in all, none of the hypotheses on primate handedness that we addressed were supported by our data. Nevertheless, when discussing conflicts between prevalent ideas and our results, we also need to address general limitations of our approach. For instance, we equate general hand preferences with tube task results. Although the tube task represents one of the best available behavioral assays for brain lateralization (Dadda et al., 2006; Margiotoudi et al., 2019), it is obvious that other hand use situations, such as gesturing, need to be considered to arrive at a holistic understanding of primate hand use evolution. Such an approach could also test how variable hand use consistency across contexts is among primates and whether ecological variables have an influence here as well. At the moment, it appears as if there is comparatively little consistency in manual preferences across different hand use situations in non-human primates (Laska, 1996; Lilak \& Phillips, 2008; Marchant \& McGrew, 2013; Caspar et al., 2018), but most studies so far compare tasks of varying complexity in a few model species and cases of consistent hand use ("true handedness") have indeed been reported (Diamond \& McGrew, 1994; Hopkins et al., 2013). Another limitation is posed by our sample composition. Both the number of species and subjects per species need to be increased to verify the patterns communicated here. In particular, additional sampling of the speciose New World monkey families Pitheciidae and Callitrichidae, tarsiers, and strepsirrhines would be desirable, to make inferences more robust. This is especially the case for predictions about hand preference patterns in early crown-group primates. Our experience suggests that at least pitheciids and lemurs only reluctantly engage in the tube task so that it might be advisable to apply different bimanual testing schemes in these groups. In lemurs, puzzle boxes have been employed as such: The animals open the lid of a box with one hand while the other one is retrieving food stored within (Regaiolli et al., 2016; Batist \& Mayhew, 2020). Future studies need to check the functional equivalence of this approach with the tube task (which is not a trivial question, compare e.g., Lilak and Phillips, 2008) to establish a set of behavioral assays that could be employed to study hand preferences in the whole primate order. These methods might then also be applied to other dexterous and ecologically variable mammalian groups, such as musteloid carnivorans (Kitchener, 2017), to test hypotheses on the evolution of manual laterality across a wider phylogenetic margin.

\section{The evolutionary issue of human handedness}

In line with previous research, we found human right-handedness to be unparalleled among primates. We want to stress, however, that humans only deviate markedly from all other taxa in direction and not in strength of lateralization for bimanual manipulation. When it comes to the latter, the human condition is approached in groups such as leaf monkeys and spider monkeys. Perhaps surprisingly, handedness strength in great apes is modest in comparison (Table 2). Still, humans are highly unusual among predominately terrestrial primates in displaying such strong individual hand preferences. Whether this difference relates to bipedal locomotion, which has often been championed as a correlate of human handedness (Westergaard et al., 1998; Cashmore et al., 
2008; Prieur et al., 2019;), is open for debate. Since no other extant primate shows similar adaptations to terrestrial bipedalism, the validity of this assumption is hard to test in the framework of comparative approaches (but see Giljov et al., 2015). Quadrupedal primates tend to exhibit stronger hand preferences when adopting the relatively instable bipedal posture (Westergaard et al., 1998). Whether this finding has any evolutionary implications remains unclear and it should be emphasized that although humans are bipeds, a high percentage of complex manual actions, including numerous examples of bimanual manipulation and tool use, are not (and never have been) habitually performed in a bipedal posture. In any case, our results suggest that bipedalism is at least not a prerequisite to evolve strong hand preferences in anthropoid primates.

When turning to lateralization direction, the statement of Corballis (1987) remains valid: some nonprimate vertebrates approach humans more closely in population-level handedness than their simian relatives do. Apart from humans, extreme forms of vertebrate limb use biases are known from parrots (Kaplan \& Rogers, 2021) and ground-living kangaroos (Giljov et al., 2015). Why these very different groups converge in this respect remains enigmatic. So why do humans stand out among the primate order when it comes to handedness direction? The limited insights gained by comparative behavioral studies, including this one, do indeed suggest that the extreme right-handedness of humans is a trait that evolved due to unique neurophysiological demands not experienced by other primates. Frost (1980) already pointed out that humans' outstanding proficiency in tool use and manufacture should be considered a significant influence on handedness evolution. Thus, not tool use per se, but the unique way in which it became immersed into complex human behaviors might have influenced overall brain lateralization in our lineage. In line with that, areas of the prefrontal cortex involved in motor cognition are structurally derived in humans and differ significantly from their homologs in apes and monkeys (Hecht et al., 2015a; Barrett et al., 2020). However, specializations of both the right and the left hemisphere are determining human-specific tool use proficiency and motor planning, apparently with particular involvement of the right inferior frontal gyrus (Ramayya et al., 2010; Hecht et al., 2015a; Hecht et al., 2015b). Postulating that hominin tool use and right-handedness evolved in tandem is therefore not straight-forward.

Besides that, there is of course the notion of coevolution between language and handedness, which might explain human-specific patterns of population-level manual lateralization. For this hypothesis to be convincing, the development and function of neural substrates controlling vocal behavior and those regulating manual motor control would need to be uniquely intertwined in humans. Indeed, the connectivity of the arcuate fasciculus, a tract critically involved in language processing and production, is highly derived in humans, suggesting important qualitative differences to other species (Rilling et al., 2008; but see Barrett et al., 2020 for other elements relevant for language production which are conserved across catarrhine primates). Nevertheless, how such traits could functionally relate to population-level handedness remains totally unclear. In fact, despite the popularity of the idea, a link between handedness and language processing that goes beyond superficial lefthemisphere collateralization in right handers (not even in the majority of left-handers) is far from evident (Fitch \& Braccini, 2013). To defend an evolutionary connection between these phenomena, pleiotropic or otherwise functionally linked genes influencing the development of both language areas and those related to handedness would need to be identified. So far, this has not been accomplished and current evidence suggests that language and handedness are largely independent on various structural levels (Ocklenburg et al., 2014; Schmitz et al., 2017b). Hence, despite the continuing efforts to unravel the evolution of human right-handedness, including the ones made by us herein, it remains an essentially unsolved issue of human cognitive evolution. 


\section{Conclusions}

We recover highly variable patterns of hand preference strength in anthropoid primates, which correlate with ecology and phylogeny. In contrast to this, no phylogenetic or ecological signal was found for lateralization direction, and few species exhibit significant population-level hand preferences. We tested three pertaining conjectures on primate handedness evolution, the $\mathrm{POH}$, tool use and brain size hypotheses, but none were supported by our data. Novel ideas on the evolution of primate hand preference should put a stronger focus on manual lateralization strength rather than direction to address the phylogenetic patterns described herein. However, additional datasets on primates and potentially non-primate mammals are needed to robustly inform respective hypotheses. By relying on standardized testing paradigms, such as the tube task, researchers can effectively build on our as well as others results and expand multispecies datasets for further comparative phylogenetic studies. Although we are convinced that such approaches could significantly improve our understanding of general trends in the evolution of primate hand preferences, the unusual autapomorphic handedness pattern of humans will very likely require explanations that cannot be derived from such comparative behavioral studies. The evolutionary underpinnings of handedness expression in our species remain enigmatic.

\section{Acknowledgements}

We would like to thank the curators and animal keepers at the following institutions for the permission to study their animals and for their support during data collection:

Allwetterzoo Münster, Apenheul (Apeldoorn), Artis Amsterdam, Bali Wildlife Rescue Center, Bioparc de Doué-la-Fontaine, Burger's Zoo (Arnhem), Erlebnis-Zoo Hannover, Howletts Wild Animal Park (Bekesbourne), Naturzoo Rheine, Parc Zoologique et Botanique de Mulhouse, Port Lympne Wild Animal Park (Lympne), Safaripark Hodenhagen, Tierpark Aachen, Tierpark Berlin, Tierpark Hamm, Tierpark Hellabrunn (Munich), Tierpark Mönchengladbach, Tierpark Ulm, Wilhelma Stuttgart, Zoo Basel, Zoo Berlin, Zoo Dortmund, Zoo Dresden, Zoo Duisburg, Zoo Frankfurt, Zoo Heidelberg, Zoo Köln (Cologne), Zoo Krefeld, Zoo Landau in der Pfalz, Zoo Liberec, Zoo Magdeburg, Zoo Neuwied, Zoo Osnabrück, Zoo Wuppertal, Zoológico de São Paulo, Zoologischer Stadtgarten Karlsruhe, ZOOM Erlebniswelt Gelsenkirchen, ZooParc Overloon, and Zoopark Erfurt.

We are also indebted to Hélène Cochet, Julia Fischer, William D. Hopkins, and Luca Morino for sharing raw data on bimanual task preferences in humans, barbary macaques, great apes, and gibbons, respectively.

Daniel Issel is greatly acknowledged for collecting data on pig-tailed macaques and Javan langurs in Bali and Petra Bolechová for doing so for Diana monkeys at Zoo Liberec. Finally, we would like to thank Miriam Lindenmeier and Larissa Günther for crucial assistance during data collection at various locations.

This research was funded by the German Society for Mammalian Biology (Deutsche Gesellschaft für Säugetierkunde). KRC was supported by a Ph.D. fellowship of the German Academic Scholarship Foundation (Studienstiftung des deutschen Volkes e.V.). 


\section{References}

Amunts, K., Schlaug, G., Schleicher, A., Steinmetz, H., Dabringhaus, A., Roland, P. E., \& Zilles, K. (1996). Asymmetry in the human motor cortex and handedness. Neurolmage, 4(3), 216-222. doi:https://doi.org/10.1006/nimg.1996.0073

Ankel-Simons, F., \& Rasmussen, D. T. (2008). Diurnality, nocturnality, and the evolution of primate visual systems. American Journal of Physical Anthropology, 137(S47), 100-117. doi:https://doi.org/10.1002/ajpa.20957

Annett, M. (2002). Handedness and Brain Asymmetry: The Right Shift Theory. Hove: Psychology Press.

Ardesch, D. J., Scholtens, L. H., de Lange, S. C., Roumazeilles, L., Khrapitchev, A. A., Preuss, T. M., . . van den Heuvel, M. P. (2021). Scaling principles of white matter connectivity in the human and nonhuman primate brain. Cerebral Cortex, bhab384. doi:10.1093/cercor/bhab384

Arnold, C., Matthews, L. J., \& Nunn, C. L. (2010). The 10kTrees website: A new online resource for primate phylogeny. Evolutionary Anthropology: Issues, News, and Reviews, 19(3), 114-118. doi:https://doi.org/10.1002/evan.20251

Barrett, R. L. C., Dawson, M., Dyrby, T. B., Krug, K., Ptito, M., Arceuil, H., . . Catani, M. (2020). Differences in frontal network anatomy across primate species. The Journal of Neuroscience, 40(10), 2094. doi:10.1523/JNEUROSCI.1650-18.2019

Barton, K. (2020). MuMIn: Multi-model inference. R package version 1.43.17. Retrieved from https://CRAN.R-project.org/package=MuMIn

Batist, C. H., \& Mayhew, J. A. (2020). Lateralization in seven lemur species when presented with a novel cognitive task. American Journal of Physical Anthropology, 172(2), 270-279. doi:https://doi.org/10.1002/ajpa.24037

Blois-Heulin, C., Bernard, V., \& Bec, P. (2007). Postural effect on manual laterality in different tasks in captive grey-cheeked mangabey (Lophocebus albigena). Journal of Comparative Psychology, 121(2), 205-213. doi:10.1037/0735-7036.121.2.205

Brown, C., \& Magat, M. (2011). The evolution of lateralized foot use in parrots: a phylogenetic approach. Behavioral Ecology, 22(6), 1201-1208. doi:10.1093/beheco/arr114

Canteloup, C., Vauclair, J., \& Meunier, H. (2013). Hand preferences on unimanual and bimanual tasks in Tonkean macaques (Macaca tonkeana). American Journal of Physical Anthropology, 152(3), 315-321. doi:https://doi.org/10.1002/ajpa.22342

Cashmore, L., Uomini, N., \& Chapelain, A. (2008). The evolution of handedness in humans and great apes: a review and current issues. Journal of Anthropological Sciences 86, 7-35.

Caspar, K. R., Mader, L., Pallasdies, F., Lindenmeier, M., \& Begall, S. (2018). Captive gibbons (Hylobatidae) use different referential cues in an object-choice task: insights into lesser ape cognition and manual laterality. PeerJ, 6, e5348. doi:10.7717/peerj.5348

Chatagny, P., Badoud, S., Kaeser, M., Gindrat, A.-D., Savidan, J., Fregosi, M., . . Rouiller, E. M. (2013). Distinction between hand dominance and hand preference in primates: a behavioral investigation of manual dexterity in nonhuman primates (macaques) and human subjects. Brain and Behavior, 3(5), 575-595. doi:https://doi.org/10.1002/brb3.160

Cochet, H., \& Vauclair, J. (2012). Hand preferences in human adults: non-communicative actions versus communicative gestures. Cortex, 48(8), 1017-1026. doi:https://doi.org/10.1016/j.cortex.2011.03.016

Corballis, M. C. (1987). Straw monkeys. Behavioral and Brain Sciences, 10(2), 269-270. doi:10.1017/S0140525X00047762

Corballis, M. C. (1991). The Lopsided Ape: Evolution of the Generative Mind. Oxford: Oxford University Press.

Coren, S., \& Porac, C. (1977). Fifty centuries of right-handedness: the historical record. Science, 198(4317), 631. doi:10.1126/science.335510

Cubí, M., \& Llorente, M. (2021). Hand preference for a bimanual coordinated task in captive hatinh langurs (Trachypithecus hatinhensis) and grey-shanked douc langurs (Pygathrix cinerea). Behavioural Processes, 187, 104393. doi:https://doi.org/10.1016/j.beproc.2021.104393 
Dadda, M., Cantalupo, C., \& Hopkins, W. D. (2006). Further evidence of an association between handedness and neuroanatomical asymmetries in the primary motor cortex of chimpanzees (Pan troglodytes). Neuropsychologia, 44(12), 2582-2586. doi:https://doi.org/10.1016/j.neuropsychologia.2006.03.037

de Andrade, A. C., \& de Sousa, A. B. (2018). Hand preferences and differences in extractive foraging in seven capuchin monkey species. American Journal of Primatology, 80(8), e22901. doi:https://doi.org/10.1002/ajp.22901

Diamond, A. C., \& McGrew, W. C. (1994). True handedness in the cotton-top tamarin (Saguinus oedipus)? Primates, 35(1), 69-77. doi:10.1007/BF02381487

Fan, P., Liu, C., Chen, H., Liu, X., Zhao, D., Zhang, J., \& Liu, D. (2017). Preliminary study on hand preference in captive northern white-cheeked gibbons (Nomascus leucogenys). Primates, 58(1), 75-82. doi:10.1007/s10329-016-0573-8

Faurie, C., Schiefenhövel, W., le Bomin, S., Billiard, S., \& Raymond, M. (2005). Variation in the frequency of left-handedness in traditional societies. Current Anthropology, 46(1), 142-147. doi:10.1086/427101

Fitch, W. T., \& Braccini, S. N. (2013). Primate laterality and the biology and evolution of human handedness: a review and synthesis. Annals of the New York Academy of Sciences, 1288(1), 70-85. doi:https://doi.org/10.1111/nyas.12071

Freckleton, R. P., Harvey, P. H., \& Pagel, M. (2002). Phylogenetic analysis and comparative data: a test and review of evidence. The American Naturalist, 160(6), 712-726. doi:10.1086/343873

Frost, G. (1980). Tool behavior and the origins of laterality. Journal of Human Evolution, 9, 447-459.

Gebo, D. L. (2011). Vertical clinging and leaping revisited: vertical support use as the ancestral condition of strepsirrhine primates. American Journal of Physical Anthropology, 146(3), 323335. doi:https://doi.org/10.1002/ajpa.21595

Giljov, A., Karenina, K., Ingram, J., \& Malashichev, Y. (2015). Parallel emergence of true handedness in the evolution of marsupials and placentals. Current Biology, 25(14), 1878-1884. doi:https://doi.org/10.1016/j.cub.2015.05.043

Häberling, I. S., \& Corballis, M. C. (2016). Cerebellar asymmetry, cortical asymmetry and handedness: two independent networks. Laterality, 21(4-6), 397-414. doi:10.1080/1357650X.2015.1110161

Harvey, P. H., \& Clutton-Brock, T. H. (1985). Life history variation in primates. Evolution, 39(3), 559581. doi:https://doi.org/10.1111/j.1558-5646.1985.tb00395.x

Hecht, E. E., Gutman, D. A., Bradley, B. A., Preuss, T. M., \& Stout, D. (2015a). Virtual dissection and comparative connectivity of the superior longitudinal fasciculus in chimpanzees and humans. Neurolmage, 108, 124-137. doi:https://doi.org/10.1016/j.neuroimage.2014.12.039

Hecht, E. E., Gutman, D. A., Khreisheh, N., Taylor, S. V., Kilner, J., Faisal, A. A., . . Stout, D. (2015b). Acquisition of Paleolithic toolmaking abilities involves structural remodeling to inferior frontoparietal regions. Brain Structure and Function, 220(4), 2315-2331. doi:10.1007/s00429014-0789-6

Hopkins, W. D. (1995). Hand preferences for a coordinated bimanual task in 110 chimpanzees (Pan troglodytes): cross-sectional analysis. Journal of Comparative Psychology, 109(3), 291-297. doi:10.1037/0735-7036.109.3.291

Hopkins, W. D. (2013a). Comparing human and nonhuman primate handedness: challenges and a modest proposal for consensus. Developmental Psychobiology, 55(6), 621-636. doi:https://doi.org/10.1002/dev.21139

Hopkins, W. D. (2013b). Neuroanatomical asymmetries and handedness in chimpanzees (Pan troglodytes): a case for continuity in the evolution of hemispheric specialization. Annals of the New York Academy of Sciences, 1288(1), 17-35. doi:10.1111/nyas.12109

Hopkins, W. D., Adams, M. J., \& Weiss, A. (2013). Genetic and environmental contributions to the expression of handedness in chimpanzees (Pan troglodytes). Genes, Brain and Behavior, 12(4), 446-452. doi:https://doi.org/10.1111/gbb.12044 
Hopkins, W. D., \& Cantalupo, C. (2004). Handedness in chimpanzees (Pan troglodytes) is associated with asymmetries of the primary motor cortex but not with homologous language areas. Behavioral Neuroscience, 118(6), 1176-1183. doi:10.1037/0735-7044.118.6.1176

Hopkins, W. D., Fernandez-Carriba, S., Wesley, M. J., Hostetter, A., Pilcher, D., \& Poss, S. (2001). The use of bouts and frequencies in the evaluation of hand preferences for a coordinated bimanual task in chimpanzees (Pan troglodytes): an empirical study comparing two different indices of laterality. Journal of Comparative Psychology, 115(3), 294-299. doi:10.1037/07357036.115.3.294

Hopkins, W. D., Gardner, M., Mingle, M., Reamer, L., \& Schapiro, S. J. (2013). Within- and betweentask consistency in hand use as a means of characterizing hand preferences in captive chimpanzees (Pan troglodytes). Journal of Comparative Psychology, 127(4), 380-391. doi:10.1037/a0031071

Hopkins, W. D., Phillips, K. A., Bania, A., Calcutt, S. E., Gardner, M., Russell, J., . . Schapiro, S. J. (2011). Hand preferences for coordinated bimanual actions in 777 great apes: implications for the evolution of handedness in hominins. Journal of Human Evolution, 60(5), 605-611. doi:10.1016/j.jhevol.2010.12.008

Kaplan, G., \& Rogers, L. J. (2021). Brain size associated with foot preferences in Australian parrots. Symmetry, 13(5). doi:10.3390/sym13050867

Karolis, V. R., Corbetta, M., \& Thiebaut de Schotten, M. (2019). The architecture of functional lateralisation and its relationship to callosal connectivity in the human brain. Nature Communications, 10(1), 1417. doi:10.1038/s41467-019-09344-1

Kimura, D. (1979). Neuromotor mechanisms in the evolution of human communication. In H. D. S. M. Paleigh (Ed.), Neurobiology of social communication in primates: An evolutionary perspective (pp. 1197-1220). Cambridge: Academic Press.

Kitchener, A. C., Meloro, C., Williams, T.M. (2017). Form and function of the musteloids. In D. W. Macdonald, Newman, C., Harrington, L. (Ed.), The Biology and Conservation of Wild Musteloids (pp. 98-135). Oxford: Oxford University Press.

Kong, X.-Z., Mathias, S. R., Guadalupe, T., Group, E. L. W., Glahn, D. C., Franke, B., ... Francks, C. (2018). Mapping cortical brain asymmetry in 17,141 healthy individuals worldwide via the ENIGMA Consortium. Proceedings of the National Academy of Sciences, 115(22), E5154. doi:10.1073/pnas.1718418115

Krasheninnikova, A., Chow, P. K. Y., \& von Bayern, A. M. P. (2020). Comparative cognition: practical shortcomings and some potential ways forward. Canadian Journal of Experimental Psychology/Revue canadienne de psychologie expérimentale, 74(3), 160-169. doi:10.1037/cep0000204

Laska, M. (1996). A study of correlates of hand preferences in squirrel monkeys (Saimiri sciureus). Primates, 37(4), 457-465. doi:10.1007/BF02381379

Laurence, A., Wallez, C., \& Blois-Heulin, C. (2011). Task complexity, posture, age, sex: Which is the main factor influencing manual laterality in captive Cercocebus torquatus torquatus? Laterality, 16(5), 586-606. doi:10.1080/1357650X.2010.501338

Lilak, A. L., \& Phillips, K. A. (2008). Consistency of hand preference across low-level and high-level tasks in Capuchin monkeys (Cebus apella). American Journal of Primatology, 70(3), 254-260. doi:https://doi.org/10.1002/ajp.20485

Lima, M. G. M., Silva-Júnior, J. d. S. e., Černý, D., Buckner, J. C., Aleixo, A., Chang, J., . . . Lynch Alfaro, J. W. (2018). A phylogenomic perspective on the robust capuchin monkey (Sapajus) radiation: First evidence for extensive population admixture across South America. Molecular Phylogenetics and Evolution, 124, 137-150. doi:https://doi.org/10.1016/j.ympev.2018.02.023

Lozano, M., Estalrrich, A., Bondioli, L., Fiore, I., Bermúdez de Castro, J.-M., Arsuaga, J. L., . . F Frayer, D. W. (2017). Right-handed fossil humans. Evolutionary Anthropology: Issues, News, and Reviews, 26(6), 313-324. doi:https://doi.org/10.1002/evan.21554

MacLean, E. L., Matthews, L. J., Hare, B. A., Nunn, C. L., Anderson, R. C., Aureli, F., .. W Wobber, V. (2012). How does cognition evolve? Phylogenetic comparative psychology. Animal cognition, 15(2), 223-238. doi:10.1007/s10071-011-0448-8 
MacNeilage, P. F. (2007). Present status of the postural origins theory. In The evolution of hemispheric specialization in primates, W. D. Hopkins (Ed.) American Society of Primatologists, pp. 59-91. Oxford: Elsevier.

MacNeilage, P. F., Studdert-Kennedy, M. G., \& Lindblom, B. (1987). Primate handedness reconsidered. Behavioral and Brain Sciences, 10(2), 247-263. doi:10.1017/S0140525X00047695

Maille, A., Belbeoc'h, C., Rossard, A., Bec, P., \& Blois-Heulin, C. (2013). Which are the features of the TUBE task that make it so efficient in detecting manual asymmetries? An investigation in two Cercopithecine species (Cercopithecus neglectus and Cercocebus torquatus). Journal of Comparative Psychology, 127(4), 436-444. doi:10.1037/a0032227

ManyPrimates, Altschul, D. M., Beran, M. J., Bohn, M., Caspar, K. R., Fichtel, C., ... Grebe, N. M. (2019). Collaborative open science as a way to reproducibility and new insights in primate cognition research. Japanese Psychological Review, 62(3), 205-220.

Marchant, L. F., \& McGrew, W. C. (2013). Handedness is more than laterality: lessons from chimpanzees. Annals of the New York Academy of Sciences, 1288(1), 1-8. doi:https://doi.org/10.1111/nyas.12062

Margiotoudi, K., Marie, D., Claidière, N., Coulon, O., Roth, M., Nazarian, B., ... Meguerditchian, A. (2019). Handedness in monkeys reflects hemispheric specialization within the central sulcus. An in vivo MRI study in right- and left-handed olive baboons. Cortex, 118, 203-211. doi:https://doi.org/10.1016/i.cortex.2019.01.001

Meguerditchian, A., Donnot, J., Molesti, S., Francioly, R., \& Vauclair, J. (2012). Sex difference in squirrel monkeys' handedness for unimanual and bimanual coordinated tasks. Animal Behaviour, 83(3), 635-643. doi:https://doi.org/10.1016/j.anbehav.2011.12.005

Meguerditchian, A., Phillips, K. A., Chapelain, A., Mahovetz, L. M., Milne, S., Stoinski, T., . . Hopkins, W. D. (2015). Handedness for unimanual grasping in 564 great apes: the effect on grip morphology and a comparison with hand use for a bimanual coordinated task. Frontiers in Psychology, 6, 1794-1794. doi:10.3389/fpsyg.2015.01794

Meguerditchian, A., Vauclair, J., \& Hopkins, W. D. (2013). On the origins of human handedness and language: A comparative review of hand preferences for bimanual coordinated actions and gestural communication in nonhuman primates. Developmental Psychobiology, 55(6), 637650. doi:https://doi.org/10.1002/dev.21150

Mittermeier, R. A., Rylands, A. B., \& Wilson, D. E. (2013). Handbook of the Mammals of the World: 3. Primates. Barcelona: Lynx Ediciones.

Morales-Jimenez, A. L., Disotell, T., \& Di Fiore, A. (2015). Revisiting the phylogenetic relationships, biogeography, and taxonomy of spider monkeys (genus Ateles) in light of new molecular data. Molecular Phylogenetics and Evolution, 82, 467-483. doi:https://doi.org/10.1016/i.ympev.2014.09.019

Morino, L., Uchikoshi, M., Bercovitch, F., Hopkins, W. D., \& Matsuzawa, T. (2017). Tube task hand preference in captive hylobatids. Primates, 58(3), 403-412. doi:10.1007/s10329-017-0605-z

Motes Rodrigo, A., Ramirez Torres, C. E., Hernandez Salazar, L. T., \& Laska, M. (2018). Hand preferences in two unimanual and two bimanual coordinated tasks in the black-handed spider monkey (Ateles geoffroyi). Journal of Comparative Psychology, 132(2), 220-229. doi:10.1037/com0000110

Musgrave, S., \& Sanz, C. (2018). Tool use in nonhuman primates. In The International Encyclopedia of Anthropology, H. Callan (Ed.). doi:https://doi.org/10.1002/9781118924396.wbiea2063

Nelson, E. L., \& Boeving, E. R. (2015). Precise digit use increases the expression of handedness in Colombian spider monkeys (Ateles fusciceps rufiventris). American Journal of Primatology, 77(12), 1253-1262. doi:https://doi.org/10.1002/ajp.22478

Ocklenburg, S., Beste, C., Arning, L., Peterburs, J., \& Güntürkün, O. (2014). The ontogenesis of language lateralization and its relation to handedness. Neuroscience \& Biobehavioral Reviews, 43, 191-198. doi:https://doi.org/10.1016/j.neubiorev.2014.04.008 
Papademetriou, E., Sheu, C.-F., \& Michel, G. F. (2005). A meta-analysis of primate hand preferences, particularly for reaching. Journal of Comparative Psychology, 119(1), 33-48. doi:10.1037/0735-7036.119.1.33

Paradis, E. S., K. (2019). ape 5.0: an environment for modern phylogenetics and evolutionary analyses in R. Bioinformatics, 35, 526-528.

Phillips, K. A., \& Sherwood, C. C. (2005). Primary motor cortex asymmetry is correlated with handedness in capuchin monkeys (Cebus apella). Behavioral Neuroscience, 119(6), 17011704. doi:10.1037/0735-7044.119.6.1701

Phillips, K. A., Sherwood, C. C., \& Lilak, A. L. (2007). Corpus callosum morphology in capuchin monkeys is influenced by sex and handedness. PLOS ONE, 2(8), e792. doi:10.1371/journal.pone.0000792

Pinheiro J., B. D., DebRoy S., Sarkar D., R Core Team. (2020). nlme: linear and nonlinear mixed effects models. R package version 3.1-148. Retrieved from https://CRAN.Rproject.org/package=nlme

Prieur, J., Lemasson, A., Barbu, S., \& Blois-Heulin, C. (2019). History, development and current advances concerning the evolutionary roots of human right-handedness and language: Brain lateralisation and manual laterality in non-human primates. Ethology, 125(1), 1-28. doi:https://doi.org/10.1111/eth.12827

Ramayya, A. G., Glasser, M. F., \& Rilling, J. K. (2010). A DTI investigation of neural substrates supporting tool use. Cerebral Cortex, 20(3), 507-516. doi:10.1093/cercor/bhp141

Raymond, M., \& Pontier, D. (2004). Is there geographical variation in human handedness? Laterality, 9(1), 35-51. doi:10.1080/13576500244000274

R Core Team (2020). R: A language and environment for statistical computing. Vienna: R Foundation for Statistical Computing. Retrieved from https://www.R-project.org/

Regaiolli, B., Spiezio, C., \& Hopkins, W. D. (2016). Hand preference on unimanual and bimanual tasks in strepsirrhines: The case of the ring-tailed lemur (Lemur catta). American Journal of Primatology, 78(8), 851-860. doi:https://doi.org/10.1002/ajp.22549

Regaiolli, B., Spiezio, C., \& Hopkins, W. D. (2018). Hand preference on unimanual and bimanual tasks in Barbary macaques (Macaca sylvanus). American Journal of Primatology, 80(3), e22745. doi:https://doi.org/10.1002/ajp.22745

Revell, L. J. (2012). phytools: an R package for phylogenetic comparative biology (and other things). Methods in Ecology and Evolution, 3(2), 217-223. doi:10.1111/j.2041-210X.2011.00169.x

Richards, G., Beking, T., Kreukels, B. P. C., Geuze, R. H., Beaton, A. A., \& Groothuis, T. (2021). An examination of the influence of prenatal sex hormones on handedness: Literature review and amniotic fluid data. Hormones and Behavior, 129, 104929. doi:https://doi.org/10.1016/j.yhbeh.2021.104929

Rilling, J. K., Glasser, M. F., Preuss, T. M., Ma, X., Zhao, T., Hu, X., \& Behrens, T. E. J. (2008). The evolution of the arcuate fasciculus revealed with comparative DTI. Nature Neuroscience, 11(4), 426-428. doi:10.1038/nn2072

Rilling, J. K., \& Insel, T. R. (1999). Differential expansion of neural projection systems in primate brain evolution. NeuroReport, 10(7), 1453-1459, doi:10.1097/00001756-199905140-00012

Ringo, J. L., Doty, R. W., Demeter, S., \& Simard, P. Y. (1994). Time is of the essence: a conjecture that hemispheric specialization arises from interhemispheric conduction delay. Cerebral Cortex, 4(4), 331-343. doi:10.1093/cercor/4.4.331

Rogers, L. J. (2009). Hand and paw preferences in relation to the lateralized brain. Philosophical Transactions of the Royal Society B: Biological Sciences, 364(1519), 943-954. doi:10.1098/rstb.2008.0225

Roos, C., Liedigk, R., Thinh, V. N., Nadler, T., \& Zinner, D. (2019). The hybrid origin of the Indochinese gray langur Trachypithecus crepusculus. International Journal of Primatology, 40(1), 9-27. doi:10.1007/s10764-017-0008-4

Sanford, C., Guin, K., \& Ward, J. P. (1984). Posture and laterality in the bushbaby (Galago senegalensis). Brain, Behavior and Evolution, 25(4), 217-224. doi:10.1159/000118867 
Schmitt, V., Melchisedech, S., Hammerschmidt, K., \& Fischer, J. (2008). Hand preferences in Barbary macaques (Macaca sylvanus). Laterality, 13(2), 143-157. doi:10.1080/13576500701757532

Schmitz, J., Metz, G. A. S., Güntürkün, O., \& Ocklenburg, S. (2017a). Beyond the genome-Towards an epigenetic understanding of handedness ontogenesis. Progress in Neurobiology, 159, 6989. doi:https://doi.org/10.1016/j.pneurobio.2017.10.005

Schmitz, J., Lor, S., Klose, R., Güntürkün, O., \& Ocklenburg, S. (2017b). The functional genetics of handedness and language lateralization: insights from gene ontology, pathway and disease association analyses. Frontiers in Psychology, 8, 1144. Retrieved from https://www.frontiersin.org/article/10.3389/fpsyg.2017.01144

Schweitzer, C., Bec, P., \& Blois-Heulin, C. (2007). Does the complexity of the task influence manual laterality in de Brazza's monkeys (Cercopithecus neglectus)? Ethology, 113(10), 983-994. doi:https://doi.org/10.1111/j.1439-0310.2007.01405.x

Sha, Z., Pepe, A., Schijven, D., Carrión-Castillo, A., Roe, J. M., Westerhausen, R., . . Francks, C. (2021). Handedness and its genetic influences are associated with structural asymmetries of the cerebral cortex in 31,864 individuals. Proceedings of the National Academy of Sciences, 118(47), e2113095118. doi:10.1073/pnas.2113095118

Silcox, M. T., Bloch, J. I., Boyer, D. M., Godinot, M., Ryan, T. M., Spoor, F., \& Walker, A. (2009). Semicircular canal system in early primates. Journal of Human Evolution, 56(3), 315-327. doi:https://doi.org/10.1016/j.jhevol.2008.10.007

Spoelstra, K. (2021). Lateralized behavior in white-handed gibbons (Hylobates lar). Master Thesis. Linköping University, Linköping.

Sussman, R. W., Tab Rasmussen, D., \& Raven, P. H. (2013). Rethinking primate origins again. American Journal of Primatology, 75(2), 95-106. doi:https://doi.org/10.1002/ajp.22096

Tab Rasmussen, D., \& Nekaris, K. (1998). Evolutionary history of lorisiform primates. Folia Primatologica, 69(Suppl. 1), 250-285. doi:10.1159/000052716

Tan, Y., Yoder, A. D., Yamashita, N., \& Li, W.-H. (2005). Evidence from opsin genes rejects nocturnality in ancestral primates. Proceedings of the National Academy of Sciences of the United States of America, 102(41), 14712. doi:10.1073/pnas.0507042102

Toth, N. (1985). Archaeological evidence for preferential right-handedness in the lower and middle pleistocene, and its possible implications. Journal of Human Evolution, 14(6), 607-614. doi:https://doi.org/10.1016/S0047-2484(85)80087-7

Vauclair, J., Meguerditchian, A., \& Hopkins, W. D. (2005). Hand preferences for unimanual and coordinated bimanual tasks in baboons (Papio anubis). Cognitive Brain Research, 25(1), 210216. doi:https://doi.org/10.1016/i.cogbrainres.2005.05.012

Ward, J. P. (1998). Left hand advantage for prey capture in the galago (Galago moholi). International Journal of Comparative Psychology, 11(4), 173-184.

Westergaard, G. C., Kuhn, H. E., \& Suomi, S. J. (1998). Bipedal posture and hand preference in humans and other primates. Journal of Comparative Psychology, 112(1), 55-64. doi:10.1037/0735-7036.112.1.55

Westergaard, G. C., \& Suomi, S. J. (1996). Hand preference for a bimanual task in tufted capuchins (Cebus apella) and rhesus macaques (Macaca mulatta). Journal of Comparative Psychology, 110(4), 406-411. doi:10.1037/0735-7036.110.4.406

Yousry, T. A., Schmid, U. D., Alkadhi, H., Schmidt, D., Peraud, A., Buettner, A., \& Winkler, P. (1997). Localization of the motor hand area to a knob on the precentral gyrus. A new landmark. Brain, 120(1), 141-157. doi:10.1093/brain/120.1.141

Zhao, D., Hopkins, W. D., \& Li, B. (2012). Handedness in nature: first evidence on manual laterality on bimanual coordinated tube task in wild primates. American Journal of Physical Anthropology, 148(1), 36-44. doi:https://doi.org/10.1002/ajpa.22038 